\title{
Cerulean Warbler population and habitat changes along Breeding Bird Survey routes in the Central Appalachians
}

\author{
Patrick Michael McElhone \\ West Virginia University
}

Follow this and additional works at: https://researchrepository.wvu.edu/etd

\section{Recommended Citation}

McElhone, Patrick Michael, "Cerulean Warbler population and habitat changes along Breeding Bird Survey routes in the Central Appalachians" (2009). Graduate Theses, Dissertations, and Problem Reports. 2776. https://researchrepository.wvu.edu/etd/2776

This Thesis is protected by copyright and/or related rights. It has been brought to you by the The Research Repository @ WVU with permission from the rights-holder(s). You are free to use this Thesis in any way that is permitted by the copyright and related rights legislation that applies to your use. For other uses you must obtain permission from the rights-holder(s) directly, unless additional rights are indicated by a Creative Commons license in the record and/ or on the work itself. This Thesis has been accepted for inclusion in WVU Graduate Theses, Dissertations, and Problem Reports collection by an authorized administrator of The Research Repository @ WVU. For more information, please contact researchrepository@mail.wvu.edu. 
Cerulean Warbler population and habitat changes along Breeding Bird Survey routes in the Central Appalachians

\author{
Patrick Michael McElhone
}

Thesis submitted to the Davis College of Agriculture, Forestry, and Consumer Sciences at West Virginia University in partial fulfillment of the requirements for the degree of

\author{
Master of Science \\ in \\ Wildlife and Fisheries Resources
}
Petra Bohall Wood, Ph.D., Chair
Deanna K. Dawson, M.S.
Michael Strager, Ph.D.

Division of Forestry and Natural Resources

Morgantown, West Virginia

2009

Keywords: aerial photo, breeding bird survey, cerulean warbler, edge density, fragmentation, habitat, national land cover dataset, off-road, population trend, roadside bias 


\section{ABSTRACT \\ Cerulean Warbler population and habitat changes along Breeding Bird Survey routes in the Central Appalachians}

\section{Patrick Michael McElhone}

Analysis of North American Breeding Bird Survey (BBS) data has identified the Cerulean Warbler (Dendroica cerulea) as a species of conservation concern with an annual population decline of $4.1 \%$ from 1966-2007. BBS data has shown persistent declines for Cerulean Warblers in their core breeding range of the Central Appalachians. No previous studies have examined the relationship between habitat change and Cerulean Warbler abundance at BBS stops, and/or whether BBS declines reflect changes occurring only at sampled routes or reflect regional Cerulean Warbler population declines. The objectives were to 1) quantify the effects of land cover and forest fragmentation metrics on Cerulean Warbler populations over several time periods along BBS stops, and 2) compare stop-level habitat and Cerulean Warbler detections between the BBS roadside surveys and an off-road dataset to determine if off-road habitat and population trends are being accurately assessed by roadside surveys.

We examined the effects of land cover and fragmentation change on Cerulean Warbler populations within a $300 \mathrm{~m}$ buffer of stops along BBS routes using aerial photos and the National Land Cover Dataset (NLCD). Aerial photos were available for 68 stops along two routes from 1967/1971 (early period) to 1982 (middle period), and from 1982/1985 (middle period) to 2000/2003 (late period) for 240 stops along six routes. Data were collected from 1,377 stops along 28 BBS routes using the 1992 and 2001 NLCD.

In aerial photo interpretation, composite land cover was replaced by deciduous/mixed forest between the early and middle time period, however deciduous/mixed forest did not change from the middle to late time period. Cerulean Warbler detections decreased between the early and middle and middle and late time periods. The lack of a change in most fragmentation variables believed to be important to Cerulean Warblers, such as interior, unfragmented deciduous forest suggests that there may be other microhabitat variables influencing the population trends of Cerulean Warblers.

From 1992 to 2001 using the NLCD, the amount of deciduous/mixed forest, amount of core forest area, and forest-forest edge density decreased. However, Cerulean Warbler detections did not change between these two time periods along the same BBS stops. When we restricted analysis to stops that had a Cerulean Warbler detected in either 1992 or 2001, we found similar responses from habitat variables over time, but Cerulean Warbler detections increased over time. The response from Cerulean Warblers along these stops may be because of the influence of microhabitat features, such as canopy gaps that we were unable to measure due to the coarse nature of the NLCD. In addition, Cerulean Warblers may be able to tolerate some degree of edge habitat, as 
Cerulean Warblers increased in the presence-only analysis as forest-nonforest edge density increased.

We compared land cover, fragmentation and physiographic metrics, and Cerulean Warbler abundance for 1,525 stops along 31 BBS routes and 1,375 off-road stops using the 2001 National Land Cover Dataset. All the land cover and six of the eight habitat variables differed between BBS and off-road datasets. Although the off-road dataset had greater amounts of habitat characteristics Cerulean Warblers seem to prefer, the BBS detected more birds per stop than the off-road dataset. BBS stops had greater densities of forest-forest and forest-nonforest edge habitat, suggesting Cerulean Warblers tolerate or select for a degree of edge in determining habitat suitability. Although three of the four land cover variables were different in presence-only analysis, nearly all of the habitat metrics and Cerulean Warbler detections were not different between the BBS and offroad datasets. From these results, we suggest that although habitat along BBS stops is different than off-road areas, Cerulean Warblers are able to find suitable habitat near roads. Since Cerulean Warblers were detected more frequently and at higher abundance along BBS stops, the estimated $4.1 \%$ annual decline from BBS data may be affecting a larger proportion of the population. 


\section{ACKNOWLEDGEMENTS}

Funding for this project was granted by the U.S. Fish and Wildlife Service, the West Virginia Division of Natural Resources, National Fish and Wildlife Foundation, and the National Council for Air and Stream Improvement. Administrative support was provided by Becky Nestor and the staffs of USGS West Virginia Cooperative Fish and Wildlife Unit and the Division of Forestry and Natural Resources at West Virginia University.

This project would not have been possible without the support, guidance, and contributions of my graduate committee members. Foremost, my major advisor Dr. Petra Wood provided me the opportunity to work on this project. Petra has been very patient, considerate, and always had an open door to answer many questions. My committee members Dr. Michael Strager made time to provide technical support for many GIS related questions. Deanna Dawson helped create the fundamental questions related to the project and provided many useful edits.

This project would never have gotten off the ground without help collecting and organizing stop coordinates. Keith Pardieck, the U.S. BBS program coordinator, and Dave Ziolkowski, a BBS program biologist took time from their hectic schedules to provide a vast majority of the BBS stop coordinates, as well as sending out a request letter to BBS volunteers asking for stop coordinate information. BBS volunteers who provided stop coordinates included: Brainard Palmer-Ball, Greg Eddy, Tom Fox, Jim Fregonara, Sue Olcott, Paul Rodewald, Kathy Shipley, Roger Thoma, and Bob Whitmore. A special thanks goes out to volunteers Howard Gratz, Wilma Jarrell, and Michael Tonkovich, who took time away from work or their weekends to accompany me collecting coordinates along routes they run. Off-road stop coordinates were provided by the West Virginia Division of Natural Resources and the Kentucky Department of Fish and Wildlife Resources.

Several individuals were instrumental providing data collection and organization support. Matt Shumar provided a large amount of GIS data to this project, helped organize data, and spent a lot of time answering many GIS-related questions. Molly McDermott, Brandon Miller, and Sandy Taylor spent many hours staring at microfiche collecting Cerulean Warbler stop-level abundance, and Molly McDermott helped organize the off-road point count dataset and organize the stop-level Cerulean Warbler abundance data.

I'd like to thank Fekedulegn Desta, who provided statistical support. I am grateful for the many afternoons he spent writing and explaining SAS coding to me.

Finally, I'd like to thanks my family and friends for providing support throughout this project. Especially, I'd like to thank Amy Bowman for support while we both navigated the path towards graduate degrees. Amy also inspired my focus and concentration, and pushed me achieve this goal. Thank you to everyone who helped, your support was much appreciated! 


\section{Table of Contents}

Abstract.

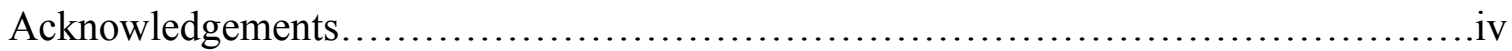

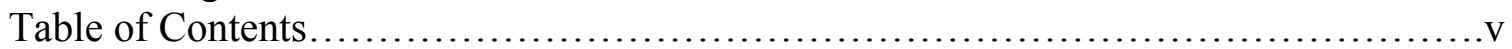

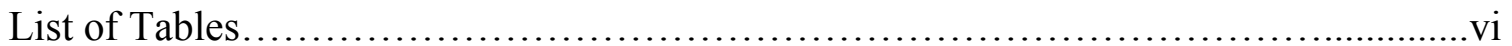

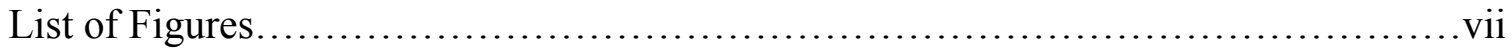

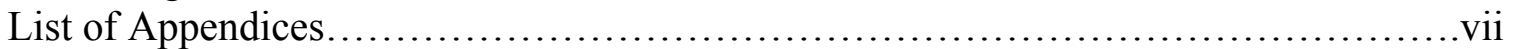

Chapter 1: Literature review of the North American Breeding Bird Survey and methods for sampling avian populations and land cover

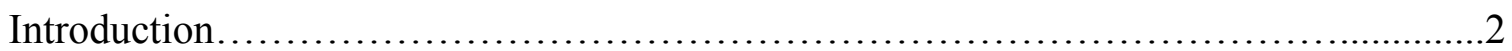

Sampling biases along Breeding Bird Survey routes................................. 3

The National Land Cover Dataset in landscape analysis............................

Literature Cited ................................................................ 11

Chapter 2: Effects of stop-level habitat change on Cerulean Warbler detections along Breeding Bird Survey routes in the central Appalachians

Abstract........................................................................... 17

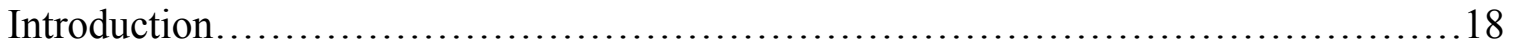

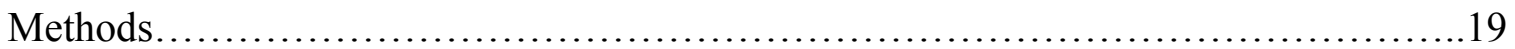

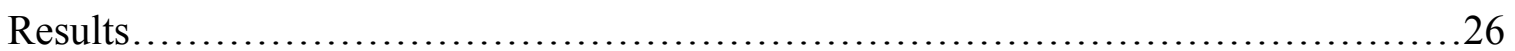

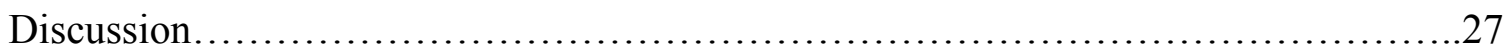

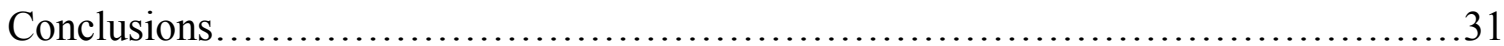

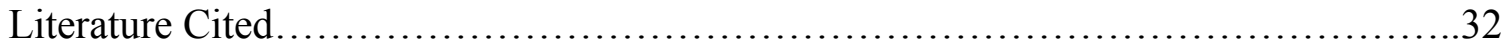

Chapter 3: Comparison of stop-level Breeding Bird Survey and off-road Cerulean Warbler abundance and land cover in the central Appalachians

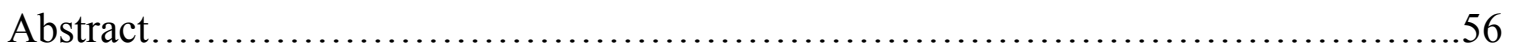

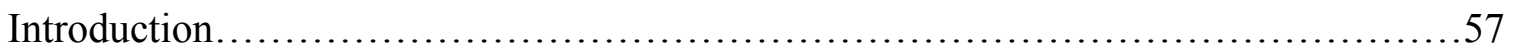

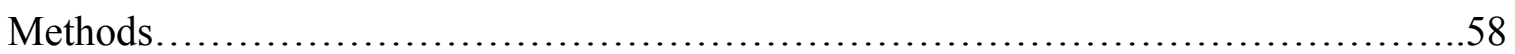

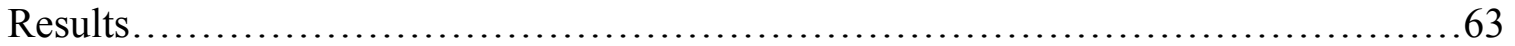

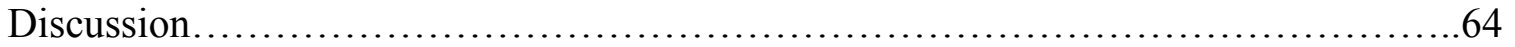

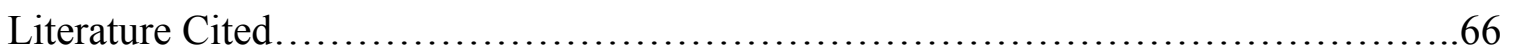




\section{List of Tables}

\section{Chapter 2:}

Table 1. Land cover and fragmentation metrics based on aerial photographs for the early (1967/1971) and middle (1982) time periods and Cerulean Warbler detections during a five year bracket surrounding each aerial photo year for 68 stops on two BBS routes....36

Table 2. Land cover and fragmentation metrics based on aerial photographs for the middle (1982/1985) and late (2000/2003) time periods and Cerulean Warbler detections during a five year bracket surrounding each aerial photo year for 240 stops on six BBS routes

Table 3. Land cover and fragmentation metrics based on aerial photographs for the middle (1982/1985) and late (2000/2003) time periods and Cerulean Warbler detections during a five year bracket surrounding each aerial photo year for 76 presence-only stops

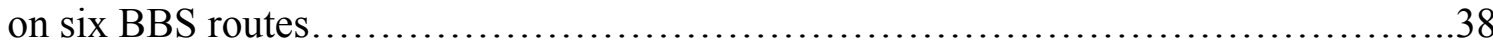

Table 4. Land cover and fragmentation metrics based on 1992 and 2001 NLCD and Cerulean Warbler detections during 1990-1994 and 1999-2003 for 1,375 stops on 28 BBS routes. $(\mathrm{FF}$ edge density $=$ Forest-forest edge density, FNF edge density $=$ Forestnonforest edge density) ........................................................

Table 5. Land cover and fragmentation metrics based on 1992 and 2001 NLCD and Cerulean Warbler detections from 1990-1994 and 1999-2003 for 344 presence-only stops along 28 BBS routes. (FF edge density = Forest-forest edge density, FNF edge density = Forest-nonforest edge density)....

Table 6. Influence of percent change in land cover on Cerulean Warblers when grouped by detection from 1992-2001 $(n=1,375)$. Cerulean Warblers are in four groups: (1) detected in 1992 and 2001 (78 stops); (2) detected in 1992, but not in 2001 (113 stops); (3) not detected in 1992, but detected in 2001 (152 stops); (4) not detected in 1992 or 2001 (1032 stops). A (+) percent change means more of that land cover was detected in 2001, a (-) percent change means more of that land cover was detected in $1992 \ldots . . . . . .41$

Table 7. Route-level Cerulean Warbler population trends for each PIF physiographic area intersecting the study area (Sauer et al. 2008) .................................. 42

\section{Chapter 3:}

Table 1. Comparison of land cover and habitat metrics using 2001 NLCD data, and Cerulean Warbler detections during 1999-2003 between the BBS $(n=1,525$ stops on 31 routes) and off-road ( $n=1,375$ stops) datasets. (FF edge density $=$ Forest-forest edge density, FNF edge density $=$ Forest-nonforest edge density) $\ldots \ldots \ldots \ldots \ldots \ldots \ldots \ldots \ldots . \ldots \ldots$ 
Table 2. Comparison of land cover and habitat metrics using 2001 NLCD data, and Cerulean Warbler detections during 1999-2003 at the set of stops at which Cerulean Warblers were detected for the BBS ( $n=253$ stops on 25 routes) and off-road $(n=169$ stops) datasets. $($ FF edge density $=$ Forest-forest edge density, FNF edge density $=$ Forest-

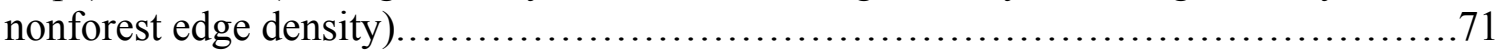

\section{Chapter 1:}

\section{List of Figures}

Figure 1. Breeding distribution of the Cerulean Warbler based on 1994-2003 BBS data. Box indicates relative abundance of Cerulean Warblers counted on BBS routes (Sauer et al. 2008)

\section{Chapter 2:}

Figure1. Study area in West Virginia, Kentucky, and Ohio portions of Partners In Flight physiographic regions Ohio Hills, N. Cumberland Plateau, and Mid Atlantic Ridge and Valley (heavy outline) with location of $28 \mathrm{BBS}$ routes with stop-level coordinates analyzed in this study....

\section{Chapter 3:}

Figure. 1. Study area of West Virginia, Kentucky, and Ohio portions of BCR-28 (dashed outline) with location of 2001 BBS routes and off-road stop locations analyzed in this study....

\section{List of Appendices}

\section{Chapter 2:}

Appendix 1. Aerial photo metadata for six BBS routes.

Appendix 2. Examples of hand-digitized land cover and reclassified NLCD within a 300 $\mathrm{m}$ buffer of the same four point count stops along BBS route 90038 .

Appendix 3. Step-by-step process to incorporate a general roads layer into the NLCD dataset. All steps were completed using the geographical information systems ArcMap, version 9.2 (ESRI, Redlands California).

Appendix 4. Forest-forest and forest-nonforest edge density calculation methods. All steps were completed using the geographical information systems ArcMap 9.2 (ESRI, Redlands, California). 
Appendix 5. Stops with $300 \mathrm{~m}$ buffer along BBS route 90038 showing land cover change from the 1992 and 2001 National Land Cover Data (NLCD). These stops are typical of the land cover surrounding BBS stops in the Appalachian region....................53

Appendix 6. Summary of each statistical analysis and model used in this study. DECp $=$ $\%$ deciduous $/$ mixed forest, $\mathrm{CONp}=\%$ coniferous forest, $\mathrm{DEVp}=\%$ developed, OTHp $=$ $\%$ other, $\mathrm{NONp}=\%$ non-forest are covariates. Metric $=$ land cover and fragmentation metrics

\section{Chapter 3:}

Appendix 1. Land cover comparison for 2001 NLCD between section of BBS route 90044 and off-road stops; both located within West Virginia. These stops are characteristic of the patchy land cover of the Appalachian region......................81 


\section{Chapter 1}

Literature Review of the North American Breeding Bird Survey and methods for sampling avian populations and land cover 


\section{INTRODUCTION}

The Cerulean Warbler (Dendroica cerulea) is a small, Neotropical migrant bird whose status recently was reviewed by the U.S. Fish and Wildlife Service, in response to a petition to place it on the threatened species list (Federal Register 2006). A major reason for concern was that analysis of data from the North American Breeding Bird Survey (BBS) indicated that range wide Cerulean Warbler populations have declined significantly over the past 40 years (-4.1\%/ year from 1966-2007, Sauer et al. 2008). This decline may have resulted in a reduction of more than $70 \%$ of the Cerulean Warbler population during this time period (W. Thogmartin pers. comm.). Although it was not placed on the list, it is still important to further understand the causes of population declines to ensure proper conservation of this species.

Cerulean Warblers breed primarily in the Ohio and Mississippi River valleys, and also in New England, southern Canada, and the Great Lakes and Appalachian Mountain regions (Fig. 1). While historically associated with riparian bottomland forest (Robbins et al. 1992), they also use mesic upland forests, particularly ridgetops, in the Appalachian region (Rosenberg et al. 2000). The Ohio Hills and Cumberland Plateau physiographic areas comprise the core of the breeding range. The wintering range includes the lower elevations of the Andes and other mountains in northern South America (Hamel 2000a).

Cerulean Warblers require large tracts of unfragmented, mature forests with tall deciduous trees to sustain viable breeding populations (Hamel 2000b, Oliarnyk 1996). Habitat loss and fragmentation due to land use changes are thought to be major factors contributing to the population declines in the core breeding range (Hamel et al. 2004). The research working group of Partners in Flight (PIF) identified the effects of land use changes on Cerulean Warbler populations in the Appalachian region as a high priority research topic (Donovan et al. 2002). Recent research has begun to assess the effects of large-scale habitat loss and fragmentation on Cerulean Warbler populations in the region (Weakland and Wood 2005, Wood et al. 2005, Wood et al. 2006). However, the relationship between long term population declines and changes in habitat has not previously been addressed. 
Within this thesis, we studied the relationship between Cerulean Warbler population changes and habitat changes along BBS routes in the core breeding range using land cover data from the National Land Cover Dataset (NLCD). This thesis is organized into three chapters that will investigate questions concerning Cerulean Warbler population trends estimated from BBS data. The first chapter reviews literature relevant to sampling biases associated with BBS data and use of the NLCD. The second chapter will examine the relationship between Cerulean Warbler detections and habitat changes at the stop-level over time along BBS routes. The third chapter concentrates on how accurately the BBS counts represents off-road areas by comparing Cerulean Warbler detections and habitat between the BBS and an off-road point count dataset.

\section{SAMPling Biases Along BreEding BiRd SuRvey Routes}

Several large-scale surveys have been used to estimate avian distributions and population trends including the Christmas Bird Count (Link et al. 2006) and state breeding bird atlases. However, the most widely distributed and analyzed survey is the North American Breeding Bird Survey (U.S. Geological Survey 2007). Although the BBS is the primary data source for population status of landbirds across North America (O'Connor et al. 2000), it has been the target of much criticism and debate over potential biases and accuracy of the estimated trends.

The BBS was established in 1966 to monitor breeding bird populations across the United States. There are currently over 4100 BBS routes across the continental U.S. and Canada, of which over 3000 are surveyed once annually during late May through early July. Each route consists of 50 stops $0.8 \mathrm{~km}$ apart (total length $40 \mathrm{~km}$ ) along secondary roads. The routes are distributed randomly through a stratification process to reduce variability and are assumed to reflect the habitats representative of that region ( $\mathrm{O}^{\prime} \mathrm{Connor}$ et al. 2000, Donovan and Flather 2002, Sauer et al. 2008). Each route is surveyed by a volunteer observer, who identifies and counts all birds seen or heard within a 3-min period at each stop.

BBS counts used in analysis of trends are summed across all 50 stops, and thus bird population changes are associated with changes in the composite of the habitats 
encountered along routes (Sauer 2000). Stop-specific changes in birds and habitats are overshadowed. A more in-depth method to determine if Cerulean Warbler population trends are accurately assessed by BBS routes may be to analyze changes in counts and habitats at each stop instead of across the entire route. Examination of stop-level changes in habitats and birds counted will allow an assessment of how these changes are affecting route-level population trends.

Furthermore, speculation also exists whether the habitats preferred by Cerulean Warblers are adequately sampled by the BBS. Mesic upland forests, particularly along ridgetops, are important habitat features for Cerulean Warblers in the core breeding range (Rosenberg et al. 2000, Weakland and Wood 2005). Microhabitat features appear to be important in Cerulean Warbler habitat selection. Aspect and slope were significant characteristics for placement of 88 Cerulean Warbler territories in southern West Virginia (Weakland and Wood 2005). Although these two key habitat features will not have changed over the 40 years of the BBS, they cannot easily be considered in route-level analyses of BBS routes. Furthermore, many of the BBS routes in West Virginia follow streams, where territory density is likely to be low (Weakland and Wood 2005).

Analyzing BBS data at the stop-level to account for the patchy habitat characteristics that are overshadowed in route-level analyses may provide the key to understanding the effectiveness of BBS data in determining Cerulean Warbler population trends.

Roadside Survey Biases.-The BBS has come under scrutiny for how accurately the counts reflect actual populations of bird species. A key feature of the original BBS design was to randomly locate routes in order to sample representative habitats within a region (Sauer et al. 2008). Presumably, changes in land cover along BBS routes should also reflect landscape changes throughout the region. All BBS routes are conducted along roads, with trends estimated from these roadside surveys considered representative of trends in regional bird populations. Assessing the extent to which habitat along BBS routes represent these regions is considered a high priority (O'Connor et al. 2000). As landscapes are altered and fragmented, changes take place in the abundance and species composition of birds detected along BBS routes. Populations of birds negatively affected by the habitat changes along roads may simply have shifted to habitat that is no longer adequately sampled by the BBS and have not in fact experienced population declines. 
Bart et al. (1995) conducted some of the first research to determine if habitat along BBS routes accurately reflects the habitat within that region. They argue that habitat changes along roads may cause data from the BBS to show a decline even when regional populations and habitat are stable. They generated 27 random points, not associated with BBS routes, in western Ohio for 1963 and 1988 and hand-digitized aerial photographs into forest cover and non-forest cover. A layer showing all roads in the area was overlaid onto the digitized aerial photos and forest cover area was quantified and compared within $140 \mathrm{~m}$ of the roads, $141-280 \mathrm{~m}$ from the roads, and within the $21 \mathrm{~km}^{2}$ surrounding area. They were unable to detect any significant changes in the amount of forest cover within these zones. However, they did find significantly less forest cover along roads than at regionwide random points for both 1963 and 1988. This study raised a fundamental question about using BBS data to make inferences about regional trends in avian abundances. If we intend to make these inferences, we must also analyze if changes in local land cover along roads reflects regional changes as well. Although Bart et al. (1995) found that changes in forest cover near roads were not representative of regional changes in forest cover for western Ohio, they recommended analyzing changes in land cover in other areas as well. Also, it is important to compare measures of land cover and bird abundance both along roads and regionally to examine if counting birds along roadside surveys is valid for making inferences at a regional scope.

Keller and Scallan (1999) also compared land cover changes along BBS routes with habitat changes in the area surrounding each route. They used aerial photos from the mid 1960s and the late 1980s to compare habitat changes within $200 \mathrm{~m}$ of BBS routes with changes $200-1,600 \mathrm{~m}$ from routes in Ohio (25 routes) and Maryland (28 routes). They did not digitize all habitat types; rather, they overlaid the photo-mosaic of each route with a grid, randomly selected 100 cells $\left(1 \mathrm{~cm}^{2}\right.$ at a scale of 1:20,000), and classified the dominant land cover type in each. Similar to Bart et al. (1995), Keller and Scallan (1999) found that similar land cover changes had occurred both near routes and away from routes, although significantly more urban land cover occurred along BBS routes than in the surrounding landscape in Maryland but not in Ohio.

Boren et al. (1999) analyzed the effects of land use changes on breeding bird community structure along BBS routes in Oklahoma. They compared bird abundances 
from 1967 to 1991 with data on vegetation cover type and landscape structure from 1966, 1973, 1980, and 1990 that was collected for another study. They found that a decrease in Neotropical migrant species was associated with a decrease in native vegetation, and an increase in road development and landscape fragmentation.

Coppedge et al. (2001) continued to research the effects of habitat changes on bird communities in Oklahoma using BBS data. They used aerial photos from 1965, 1981, and 1995 to assess changes in landscape within a $0.4 \mathrm{~km}$ radius of each stop for three BBS routes over 30 years. They used mean species abundance at each stop for two time periods, 1965-1981 and 1981-1995, to compare changes in route-level landscape with changes in species abundance. It was determined that habitat changes along these routes have resulted in a change in the avian community structure. Similar to the work of Boren et al. (1999), this study continues to answer the question of how habitat change along roads influences counts of avian abundance and raises the question of whether the documented habitat changes along BBS routes reflect changes in regional habitat. If regional habitat is changing at a different rate or scale than near BBS routes, the BBS route is no longer representative of that region. Also, trends in bird populations from BBS routes will no longer be representative of bird population trends in the region. Further research needs to address the question of whether or not habitat changes along BBS routes reflect habitat changes in the region the route is intended to represent and the influence of these habitat changes on bird population trends both near roads and in the surrounding landscape.

Harris and Haskell (2007) quantified roadside sampling bias in Tennessee by comparing land cover proportions near roads to proportions of the entire landscape in the state. For the seven-county area of the southern Cumberland Plateau physiographic region, land cover for 1980, 1990, 1997, 2000, and 2003 was digitized along roads at buffers of $50 \mathrm{~m}, 200 \mathrm{~m}$, and $400 \mathrm{~m}$ using aerial photographs. They also compared land cover proportions along BBS routes to the land cover proportions for the entire state of Tennessee using data derived from Landsat Thematic Mapper satellite imagery. They found similar results for both analyses in that roadside habitats provided a biased estimate of the actual land cover for the region. Overall, urban/developed areas were overrepresented and upland deciduous forests were under-represented along BBS routes. 
They also used point count data from 2000 and 2001 from the Cumberland Plateau to model estimates of population trends for five species, and compared their estimates from the entire landscape with those from the roadside surveys to determine how roadside sampling may bias estimates of bird populations. They found that roadside surveys underestimated population declines of species that breed in mature forests (deciduous forest with $70-100 \%$ intact forest canopy). These results indicate the necessity of further research into the biases associated with the roadside sampling method of the BBS.

The assumption that habitat change and avian abundance trends along BBS routes are representative of regional habitat and avian trend changes also was recently challenged by Betts et al. (2007). They tested whether changes in mature forest within $150 \mathrm{~m}$ of BBS routes were representative of the mature forest within $1^{\circ}$ blocks of latitude and longitude in New Brunswick, Canada, and if the habitat changes along BBS routes affect population trends of the Blackburnian Warbler (Dendroica fusca). The study was conducted over three time periods (1970s, 1980s, and 1990s) and found mature forest within $150 \mathrm{~m}$ of BBS routes was significantly less than in the surrounding $1^{\circ}$ blocks for each time period. Over the entire time span, the rate of mature forest change was not significantly different between the BBS routes and the degree blocks. However, when time periods were analyzed separately, mature forest declined 4.8 times faster within degree blocks than along BBS routes for the 1970s and 1980s. Finally, the BBS population trend for Blackburnian Warbler was correlated with the trend in mature forest along BBS routes. Therefore, regional population trends may have been biased in the 1970s and 1980s because mature forests along BBS routes were declining at a slower rate than within the surrounding degree blocks. This study demonstrates that because habitat changes along BBS routes may not be representative of regional landscape changes, BBS data may give biased population trends for avian species and mask the actual population trends occurring within the region. Still, further analysis between stop-level habitat and avian abundance change may lead to more accurate estimation of causes for avian population change.

The roadside sampling design of the BBS has created questions about how accurately this survey can measure regional avian population trends. Changes in land cover along BBS routes may not reflect regional changes in land cover, which can lead to 
biased avian population trend estimates. Habitat changes along BBS routes may negatively affect estimates of regional Cerulean Warbler population trends. If suitable Cerulean Warbler habitat along BBS routes has been changing to unsuitable habitat over the past 40 years, these birds will not be detected as often as previously, leading to a declining population trend from BBS data. Research needs to address whether the estimated declines in Cerulean Warbler populations reflect actual population declines or simply changes in habitat sampled along BBS routes.

On-road Versus Off-road Point Counts. - Point count surveys have been widely implemented to measure relative abundance and population trends for many avian species. A primary consideration is whether point count locations should be on or offroad. Many more point count locations can be visited during a day or season along roadside surveys, allowing more area to be surveyed. However, roadside surveys may not sample all the habitats within a study area, or roads themselves may create unique habitat types. It has even been suggested that measures of relative abundance taken from counts along roads may differ from those within interior habitat (Ralph et al. 1995). This raises the question of whether roadside surveys are the most accurate source of population status data for interior deciduous forest species, such as the Cerulean Warbler.

Concerns have been raised as to whether or not birds of a region can accurately be sampled through point counts in roadside habitats. Hanowski and Niemi (1995) addressed this issue in northern Minnesota, comparing point counts that were randomly placed along a road to counts conducted at least $200 \mathrm{~m}$ from a road for one year. They also compared point counts from roads with counts in the same habitat type at least 200 $\mathrm{m}$ away from the road over a three year period. In the first comparison, they found more species on average in the roadside points than the off-road points, mainly due to the openings and shrub habitat found along the road. In the second comparison, they found similar results in the abundances and species recorded between the paired within-habitat points. They suggested that roadside point counts can adequately survey birds within a region as long as they are randomly placed within specific habitat types, and recommended that roads selected for sampling have a closed canopy. Off-road points should be used to sample habitat types not present along roads. 
Rotenberry and Knick (1995) also found that roadside point count surveys detected similar abundances of birds as off-road surveys within grassland and shrubsteppe habitat of southwestern Idaho. They paired a roadside point count with one greater than $400 \mathrm{~m}$ away from the road but in a similar habitat. They acknowledged, however, that roads in these habitats may play a much smaller role in causing habitat fragmentation and creating edge effects than roads in structurally diverse woodlands and forests.

Similar research has been conducted in the Shenandoah National Park, Virginia (Keller and Fuller 1995), and northern Montana (Hutto et al. 1995). Both studies collected point count data from the roadside out to at least $200 \mathrm{~m}$ perpendicular from the road, in areas where the forest type remained constant to at least $400 \mathrm{~m}$ from the road. In both studies, no species had a significantly different abundance for off-road points than roadside points. However, more species and individuals were detected at roadside points than at off-road points. It needs noting that these results are useful if habitat type does not change as point counts are conducted further away from roads. It is unknown if similar results would apply to BBS routes where habitat types may change off-road of the routes.

In summary, there continues to be debate whether point counts should be placed off-road to accurately sample bird population trends. Studies have generally found that point counts can be placed along roads if the habitat is the same as off-road. However, major habitat types may not be sampled by roads. The interior, deciduous forest habitat requirements of the Cerulean Warbler make it a species susceptible to biased population trends on BBS roadside surveys.

\section{The National LAND Cover DATASET in LANDSCAPE ANALYSIS}

The NLCD was created to provide a consistent land cover dataset for the conterminous United States in a framework that allows a wide range of geographical management and analysis applications (Homer et al. 2004). It was created in 1992 from satellite imagery from Landsat 5, and updated in 2001 with Landsat 7 imagery, using Anderson I and II land cover classes (Anderson 1976). 
The NLCD is becoming one of the most widely used tools to analyze landscapes for environmental research and management. However, since this new technology is still developing, there are limitations in its accuracy. Thogmartin et al. (2004) identified inconsistencies in the NLCD and offered solutions to overcome these problems. They observed mapping inconsistencies along borders between zones, states, and Thematic Mapper mapping paths for their study area in the upper Midwestern U.S. To overcome these inconsistencies for modeling bird populations, they combined several land cover types and excluded others from their analyses. This study explains why it is important to identify land cover types of the NLCD that Cerulean Warblers use as habitat and keep these as separate categories and combine land cover types that are not important Cerulean Warbler habitat.

Another possibility of error using the NLCD arises because the 1992 and 2001 versions had somewhat different land cover classification schemes (Vogelmann et al. 2001, Homer et al. 2004). Wickham et al. (2007) addressed this issue in a study quantifying the effects of mountaintop mining on interior Appalachian forests. They followed a six-step process to reclassify the two NLCD data sets to determine the change in interior forest. An alternative method is to use forest cover type as a reference guide since it is fairly accurate based on 1992 NLCD (Stehman et al. 2003).

Conclusions.-These previous studies have collectively shaped the background for further research into the effects of land cover changes along BBS routes on estimates of Cerulean Warbler populations. While some of these studies have begun to research the effectiveness and accuracy of BBS data on bird species guilds, none have focused specifically on Cerulean Warblers. Also, none have analyzed BBS data at the stop-level, which may provide critical information describing Cerulean Warbler population declines, as well as an alternative method to analyze BBS data. An analysis comparing stop-level changes in Cerulean Warbler populations and land cover along BBS routes will provide useful information for this species of special conservation concern. 


\section{LITERATURE CiTED}

Anderson, J.F., E.E. Hardy, J.T. Roach, and R.E. Witmer. 1976. A land use and land cover classification system for use with remote sensor data, U.S. Geological Survey Professional Paper 964. U.S. Geological Survey, Washington, DC.

Bart, J., M. Hofschen, and B.G. Peterjohn. 1995. Reliability of the Breeding Bird Survey: effects of restricting surveys to roads. Auk 112: 758-761.

Betts, M.G., D. Mitchell, A.W. Diamond, and J. Bêty. 2007. Uneven rates of landscape change as a source of bias in roadside wildlife surveys. Journal of Wildlife Management 71: 2266-2273.

Boren, J.C., D.M. Engle, M.W. Palmer, R.E. Masters, and T. Criner.1999. Land use change effects on breeding bird community composition. Journal of Range Management 52: 420-430.

Coppedge, B.R., D.M. Engle, R.E. Masters, and M.S. Gregory. 2001. Avian response to landscape change in fragmented southern Great Plains grasslands. Ecological Applications 11:47-59.

Donovan, T.M., C.J. Beardmore, D.N. Bonter, J.D. Brawn, R.J. Cooper, J.A. Fitzgerald, R. Ford, S.A. Gauthreaux, T.L. George, W.C. Hunter, T.E. Martin, J. Price, K.V. Rosenberg, P.D. Vickery, and T.B. Wigley. 2002. Priority research needs for the conservation of Neotropical migrant landbirds. Journal of Field Ornithology 73: 329339.

Donovan, T.M., and C.H. Flather. 2002. Relationships among North American songbird trends, habitat fragmentation, and landscape occupancy. Ecological Applications 12: 364-374.

Federal Register. 2006. Endangered and Threatened Wildlife and Plants; 12-month finding on a petition to list the Cerulean Warbler (Dendroica cerulea) as threatened with critical habitat. 71(234): 70717-70733.

Hamel, P. B. 2000a. Cerulean Warbler status assessment. U.S. Fish and Wildlife Service. [Online.] Available at www.fws.gov/midwest/eco_serv/soc/birds/cerw/cerw-sa.pdf.

Hamel, P.B. 2000b. Cerulean Warbler (Dendroica cerulea). In The Birds of North America, no. 511 (A. Poole and F. Gill, Eds.). Academy of Natural Sciences, Philadelphia, and American Ornithologists' Union, Washington, D.C.

Hamel, P.B., D.K. Dawson, and P.D. Keyser. 2004. How we can learn more about the Cerulean Warbler (Dendroica cerulea). Auk 121: 7-14. 
Hanowski, J.M., and G.J. Niemi. 1995. A comparison of on- and off-road bird counts: Do you need to go off road to count birds accurately? Journal of Field Ornithology 66: 469-483.

Harris, J.B.C., and D.G. Haskell. 2007. Land cover sampling biases associated with roadside bird surveys. Avian Conservation and Ecology - Ecologie et conservation des oiseaux 2:12 [Online.] Available at www.ace-eco.org/vol2/iss2/art12/.

Homer, C., C. Huang, L. Yang, B. Wylie, and M. Coan. 2004. Development of a 2001 National Land-Cover Database for the United States. Photogrammetric Engineering and Remote Sensing 70: 829-840.

Hutto, R.L., S.J. Hejl, J.F. Kelly, and S.M. Pletschet. 1995. A comparison of bird detection rates derived from on-road versus off-road point counts in northern Montana. Pages 103-110 in Monitoring Bird Populations by Point Counts (C.J. Ralph, J.R. Sauer, and S. Droege, Eds.). USDA Forest Service General Technical Report PSW-GTR-149, Albany, CA.

Keller, C.M.E., and M.R. Fuller. 1995. Comparison of birds detected from roadside and off-road point counts in the Shenandoah National Park. Pages 111-115 in Monitoring Bird Populations by Point Counts (C.J. Ralph, J.R. Sauer, and S. Droege, Eds.). USDA Forest Service General Technical Report PSW-GTR-149, Albany, CA.

Keller, C.M.E., and J.T. Scallan. 1999. Potential roadside biases due to habitat changes along Breeding Bird Survey routes. Condor 101:50-57.

Link, W.A., J.R. Sauer, and D.K. Niven. 2006. A hierarchical model for regional analysis of population change using Christmas Bird Count data, with application to the American Black Duck. The Condor 108: 13-24.

O’Connor, R.J., E. Dunn, D.H. Johnson, S.L. Jones, D. Petit, K. Pollock, C.R. Smith, J.L. Trapp, and E. Welling. 2000. A programmatic review of the North American Breeding Bird Survey. Report of a peer review panel. Patuxent Wildlife Research Center, Laurel, Maryland. [Online]. Available at www.pwrc.usgs.gov/BBS/bbsreview/bbsfinal.pdf

Oliarnyk, C.J. 1996. Habitat selection and reproductive success in a population of Cerulean Warblers in southeastern Ontario. M.S. Thesis, Queen's University, Kingston, Ontario, Canada.

Ralph, C.J., S. Droege, and J.R. Sauer. 1995. Managing and monitoring birds using point counts: standards and applications. Pages 161-169 in Monitoring Bird Populations by Point Counts (C.J. Ralph, J.R. Sauer, and S. Droege, Eds.). USDA Forest Service General Technical Report PSW-GTR-149, Albany, CA.

Robbins, C. S., J. W. Fitzpatrick, and P. B. Hamel. 1992. A warbler in trouble: Dendroica cerulea. Pages 549-562 in Ecology and Conservation of Neotropical 
Migrant Landbirds (J.M. Hagan III and D.W. Johnston, Eds.). Smithsonian Institution Press, Washington, D.C, USA.

Rosenberg, K.V., S.E. Barker, and R.W. Rohrbaugh. 2000. An atlas of Cerulean Warbler Populations-Final Report to the USFWS: 1997-2000 Breeding Seasons. Cornell Laboratory of Ornithology, Ithaca, New York.

Rotenberry, J.T, and S.T. Knick. 1995. Evaluation of bias in roadside point count surveys of passerines in shrubsteppe and grassland habitat in southwestern Idaho. Pages 99101 in Monitoring Bird Populations by Point Counts (C.J. Ralph, J.R. Sauer, and S. Droege, Eds.). USDA Forest Service General Technical Report PSW-GTR-149, Albany, CA.

Sauer, J.R. 2000. Combining information from monitoring programs: complications associated with indices and geographic scale. Pages 124-127 in Strategies for bird conservation: The Partners in Flight planning process (R. Bonney, D.N. Pashley, R.J. Cooper, and L. Niles, Eds.). U.S. Department of Agriculture, Forest Service Research Station Proceeding RMRS-P-16.

Sauer, J.R., J.E. Hines, and J. Fallon. 2008. The North American Breeding Bird Survey, Results and Analyses 1966 - 2007. version 5.15.2008. U.S. Geological Survey Patuxent Wildlife Research Center, Laurel, Maryland. [Online.] Available at www.mbr-pwrc.usgs.gov/bbs/bbs.html.

Stehman, S.V., J.D. Wickham, J.H. Smith., and L. Yang. 2003. Thematic accuracy of the 1992 National Land Cover Dataset for the eastern United States: statistical methodology and regional results. Remote Sensing of Environment 86: 500-516.

Thogmartin, W. 2006. Unpublished data. Results of diffusion approximation extinction risk model for Cerulean Warbler. 20 pp. Wayne Thogmartin, US Geological Survey, Biological Resources, Upper Midwest Environmental Sciences Center, La Crosse, WI.

Thogmartin, W.E., A.L. Gallant, M.G. Knutson, T.J. Fox, and M.J. Suárez. 2004. A cautionary tale of the National Land Cover Dataset 1992. Wildlife Society Bulletin 32: $960-968$.

U.S. Geological Survey, 2007. Strategic plan for the North American Breeding Bird Survey: 2006-2010: U.S. Geological Survey Circular 1307, 19 p. [Online] Available at pubs.usgs.gov/circ/2007/1307/pdf/circ1307.pdf.

Vogelmann, J.E., S.M. Howard, and C.R. Larson. 2001. Completion of the 1990s National Land Cover Data set for the conterminous United States from Landsat Thematic Mapper data and ancillary data sources. Photogrammetric Engineering and Remote Sensing. 67: 650-662. 
Weakland, C.A., and P.B. Wood. 2005. Cerulean Warbler (Dendroica cerulea) microhabitat and landscape-level habitat characteristics in southern West Virginia. Auk 122: 497-508.

Wickham, J.D., K.H. Riitters, T.G. Wade, M. Coan, and C. Homer. 2007. The effect of Appalachian mountaintop mining on interior forest. Landscape Ecology 22: 179-187.

Wood, P.B., S. Bosworth, and R. Dettmers. 2006. Cerulean Warbler abundance and occurrence relative to large-scale edge and habitat characteristics. Condor 108:154165.

Wood, P.B., J.P. Duguay, and J.V. Nichols. 2005. Cerulean Warbler use of regenerated clearcut and two-age harvests. Wildlife Society Bulletin 33: 851-858. 


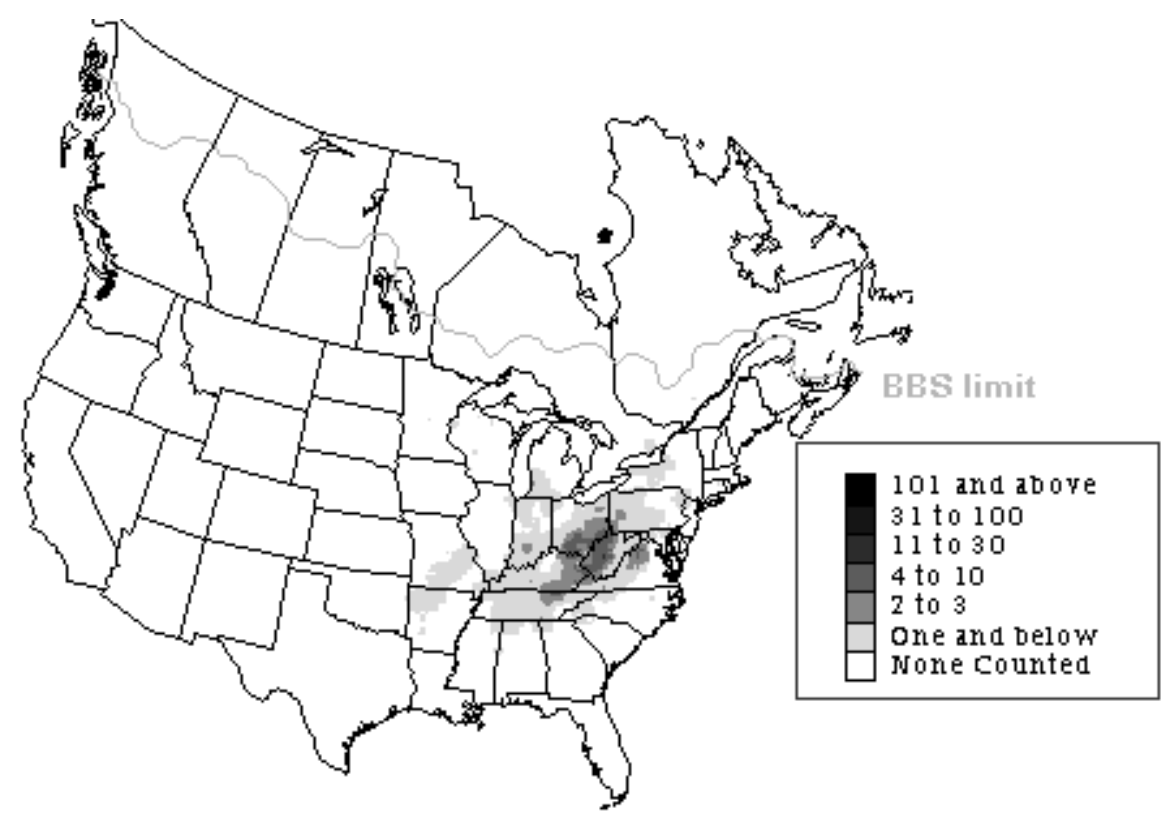

Figure 1. Breeding distribution of the Cerulean Warbler based on 1994-2003 BBS data. Shading indicates number of Cerulean Warblers counted on BBS routes (Sauer et al. 2008). 


\section{Chapter 2}

\section{Effects of stop-level habitat change on Cerulean Warbler detections along Breeding}

Bird Survey routes in the central Appalachians

Formatted in the style of Wilson Journal of Ornithology 
Abstract.--- Analysis of North American Breeding Bird Survey (BBS) data has identified the Cerulean Warbler (Dendroica cerulea) as a species of conservation concern with an annual population decline of $4.1 \%$ from 1966-2007. This study examined the effects of habitat change on Cerulean Warbler populations at stops along BBS routes in the central Appalachians from 1967/1971 (early period) to 1982 (middle period) for two routes, and from 1982/1985 (middle period) to 2000/2003 (late period) for six routes based on aerial photos, and for 28 routes based on the 1992 and 2001 National Land Cover Datasets (NLCD). In aerial photo interpretation, deciduous/mixed forest replaced the composite land cover type between the early and middle time period but did not change from the middle to late time period. Cerulean Warbler detections decreased between the early and middle and between the middle and late time periods. Since the composite land cover category is dominated by agricultural fields in the study area, it is possible fields were abandoned and either early-stage forests developed or the fields were converted to development. The lack of a change in most habitat variables believed to be important to Cerulean Warblers, such as interior, unfragmented deciduous forest suggests that there may be other microhabitat variables influencing the population trends of Cerulean Warblers. From 1992 to 2001 within a 300-m buffer around each BBS stop, the amount of deciduous/mixed forest, amount of core forest area, and forest-forest edge density decreased, whereas the amount of non-forest land cover increased. Cerulean Warbler detections did not change between these two time periods along the same BBS stops. When we restricted analysis to stops that had a Cerulean Warbler detected in either 1992 or 2001, we found similar responses from habitat variables over time, but Cerulean Warbler detections increased over time. One possible reason for the response from Cerulean Warblers along these stops could be the influence of microhabitat features, such as canopy gaps that we were unable to measure due to the coarse nature of the NLCD. In addition, Cerulean Warblers seem to be able to tolerate some degree of edge habitat, as Cerulean Warblers increased in the presence-only analysis as forest-nonforest edge density increased. As more stop-level coordinates are collected along BBS routes, the accuracy of this type of analysis will increase in determining how habitat changes at BBS stops are influencing Cerulean Warbler population trends. 


\section{INTRODUCTION}

The Cerulean Warbler (Dendroica cerulea), a small, Neotropical migrant bird species of conservation concern, was recently reviewed for listing as a threatened species by the U.S. Fish and Wildlife Service (Federal Register 2006). Analysis of data from the North American Breeding Bird Survey (BBS) determined that Cerulean Warbler populations range-wide declined significantly at 4.1\% per year during 1966-2007 (Sauer et al. 2008). The consistent decline of Cerulean Warblers in the core breeding range over the 40 years of the BBS has elevated this species to a high level of conservation concern, and led to creation of the Cerulean Warbler Technical Group (Hamel et al. 2004).

Cerulean Warblers breed primarily in the Ohio and Mississippi River valleys, with the Ohio Hills and Cumberland Plateau physiographic areas comprising the core breeding range (Hamel 2000a). Within the core range, mesic upland forests, particularly ridgetops, are important habitat (Rosenberg et al. 2000, Weakland and Wood 2005). Cerulean Warblers require large tracts of unfragmented, mature forests with tall deciduous trees to sustain viable breeding populations (Oliarnyk 1996, Hamel 2000b).

Habitat loss and fragmentation due to land use changes are thought to be major factors contributing to declining populations in the core breeding range (Hamel et al. 2004), where some of the steepest declines have occurred (Sauer et al. 2008). Donovan et al. (2002) identified the effects of land use changes on Cerulean Warbler populations in the Appalachian region as high priority research. Recent research has begun to assess the effects of large-scale habitat loss and fragmentation on Cerulean Warbler populations in the region (Weakland and Wood 2005, Wood et al. 2005, Wood et al. 2006). Analysis of the relationship of changes in Cerulean Warbler counts and habitats along BBS routes in the core breeding range will provide insights on the role that habitat change plays in long-term population declines.

The BBS, established in 1966 to monitor breeding bird populations, is the primary data source for population status of landbirds across North America (O'Connor et al. 2000). Each $40 \mathrm{~km}$ BBS route consists of 50 point count stops $0.8 \mathrm{~km}$ apart along secondary roads. The routes are distributed randomly and are assumed to reflect habitats representative of that region (Donovan and Flather 2002). Once a year, a volunteer 
observer identifies and counts all birds seen or heard within a 3-min period at each stop along a route (North American Breeding Bird Survey 2001). BBS counts used in analysis of population trends are summed across all 50 stops, thus are associated with the composite of the habitats encountered and stop-specific changes in habitat are overshadowed (Sauer 1999). A more in-depth method to determine how habitat changes affect Cerulean Warbler population trends on BBS routes may be to analyze count data and habitat changes at each stop instead of across the entire route. Small scale habitat characteristics, including slope position, aspect, and microhabitat features such as canopy gaps, can affect Cerulean Warbler abundance (Weakland and Wood 2005, Perkins 2006); these features are lost when habitat is analyzed at the route level. Examination of stoplevel changes in habitats and birds counted will allow an assessment of how these changes are affecting route-level population trends.

In this paper, we examine the association between Cerulean Warbler population changes and habitat changes along BBS routes in the core breeding range. Specifically, we (1) analyzed the effects of land cover and forest fragmentation changes, measured from aerial photos, on Cerulean Warbler populations over three time periods for a subsample of BBS routes; and (2) quantified land cover and forest fragmentation metrics over two time periods using National Land Cover Data (NLCD) to examine habitat changes on Cerulean Warbler populations along a broader sample of BBS routes.

\section{METHODS}

Study Area. --- We used data from BBS routes within the West Virginia, Kentucky, and Ohio portions of Bird Conservation Region (BCR) 28-Appalachian Mountains (Fig. 1). BCR 28 is generally classified as dominated by oak (Quercus spp.)hickory (Carya spp.) and associated deciduous tree species at lower elevations, and by northern hardwoods and spruce or fir at higher elevations. The study area falls within the NLCD mapping zones of 47, 53, 61, and 62 (Homer et al. 2004).

The Ohio Hills, Northern Cumberland Plateau, and Mid Atlantic Ridge and Valley physiographic areas (www.partnersinflight.org/bcps/pifplans.htm) of BCR 28

comprise the majority of the study area, which is considered the core breeding range of 
the Cerulean Warbler (Hamel 2000a). The Ohio Hills ( $\sim 8$ million ha) is characterized by dissected plateaus ranging from 150 - $450 \mathrm{~m}$ in elevation (Rosenberg 2000). Oak-hickory forests cover roughly $54 \%$ of this region. Agriculture and urban/developed areas are the other dominant land cover types, covering $40 \%$ of the region. The Northern Cumberland Plateau ( $\sim 5.5$ million ha) is a rolling hills tableland ranging from $300-580 \mathrm{~m}$ in elevation (Demarest 2003). This is one of the most heavily forested physiographic areas in the eastern U.S.; the most common land cover type is mixed mesophytic forests dominated by oaks and hickories. The species composition and vegetative structure within these forests differ from historical conditions, as widespread timber harvesting and fire suppression have limited old-growth and early-successional habitat. The Mid Atlantic Ridge and Valley region ( $\sim 5$ million ha) is dominated by long mountainous ridges and intervening valleys (Rosenberg 1999). Similar to the other physiographic areas, the vegetation primarily consists of oak-hickory forests. While human populations remain relatively sparse, natural resource extraction is an important land use of the area (Pashley et al. 2000).

Data Collection. --- We used data from BBS routes within the study area that met the following criteria: (1) one or more Cerulean Warbler was detected along the routes in at least one time period; (2) they had stop-level coordinates collected by the BBS route observers; and (3) they were surveyed at least three times within a five-year time bracket for each year of available land cover data. Each selected route needed to have Cerulean Warbler detections within at least one time period because this study is focused on how change in land cover and habitat have affected Cerulean Warbler detections; routes that never had a single detection lack this information. We only included BBS routes with stop-level coordinates collected by observers so we could place stop locations as accurately as possible; although stops are set at $0.8 \mathrm{~km}$ intervals, observers sometimes adjust stop locations to safer or quieter stopping points (D. Dawson, pers. comm.), so stop locations mapped by BBS staff are not always accurate. We used data from multiple years to better identify stops at which Cerulean Warblers were present. Birds can easily be missed in a 3-min counting period, so birds not detected cannot be assumed to be absent. Also, some BBS routes are not run every year; to include as many routes as possible, we required only that they be surveyed at least three times within the five-year 
time bracket around each year of land cover data used, with surveys from all five years being optimum. The three- to five-year period also may provide a more accurate measure of the response of migratory birds to habitat changes than data from only one year, which would be more of a snapshot in time. Using BBS data from years that bracket the land cover data ensures that the land cover will be representative of conditions when the routes were sampled.

Land cover data can be measured from several remotely-sensed data sources; in this study we used both aerial photos and the NLCD. Aerial photos have been taken occasionally within the study area over the more than 40 years that BBS data have been collected, so are most suited to investigate long-term changes in land cover along BBS routes. However, aerial photos are spatially limited and do not provide complete coverage of many BBS routes, and hand-digitizing land cover from aerial photos is very time-consuming. The NLCD allows land cover to be quickly assessed for a broader extent of BBS routes, but is limited to 1992 and 2001. For these reasons, this study used aerial photos to examine long-term land cover changes at a small number of BBS stops, and NLCD data to quantify changes in land cover over a 10 -year period for a larger number of BBS routes.

The time frame in which aerial photo data were collected was separated into three periods: 1967/1971 (early time period), 1982/1985 (middle time period), and 2000/2003 (late time period; Appendix 1) to correspond with years that aerial photos were available. Of the $88 \mathrm{BBS}$ routes in the study area, six met the criteria for inclusion in the long-term aerial photo analysis (five routes in West Virginia, one in Ohio; Appendix 1). Photos for the late time period from West Virginia are geo-referenced 2003 natural color orthophotos from the Statewide Address and Mapping Board (WV SAMB), downloaded from the WV GIS State Technical Center (http://wvgis.wvu.edu/index.php). The Ohio route photos were rectified from 2004 National Agriculture Imagery Program (NAIP) natural color county mosaics acquired from the USDA Geospatial Data Gateway (http://datagateway.nrcs.usda.gov/GatewayHome.html). All other photos were obtained from USGS Earth Explorer (http://earthexplorer.usgs.gov/) and are either color infrared or black and white from several different programs (Appendix 1). Aerial photos were rectified using the WV SAMB 2003 or the NAIP 2004 digital orthophotos. Photos from 
all time periods were rectified and digitized using Albers projection in ArcMap, version 9.2 geographical information systems (GIS; ESRI, Redlands, California) software. The aerial photos used were taken during leaf-off from October through early May, when it is easiest to distinguish coniferous from deciduous trees.

Aerial photos were available for 68 stops on two BBS routes per time period from the early to middle time period, and for 240 stops on six routes per time period from the middle to late time period. We digitized land cover into four types: deciduous/mixed forest, coniferous forest, developed, and composite. We distinguished between deciduous/mixed and coniferous forests because Cerulean Warblers are not known to use coniferous forests (Hamel 2000b). The composite land cover collapsed all remaining types not included by the three other land cover types.

Twenty-eight BBS routes met the aforementioned criteria to be included in the comparison of the 1992 and 2001 NLCD data; from these, land cover was measured around 1,375 stops per time period. Although development may be an important land cover class that is changing over time along BBS routes, we chose not to classify this type for the NLCD dataset. In the 1992 NLCD land cover classification, small, secondary roads were not classified, but they were classified as the developed type in 2001 (Vogelmann et al. 2001, Homer et al. 2004). Therefore, an increase in developed area around a BBS stop may be because of the different method of classification, not a change in land cover type. For this reason, we combined the developed and composite land cover types into a non-forest land cover class. Although successional stage of a forest may be a useful land cover criterion, the 30-m resolution makes distinguishing early successional habitat difficult (NLCD 2007). Finer distinctions between specific land cover types are unnecessary and may not be valid (Thogmartin et al. 2004, Wickham et al. 2007) at a broad scale in determining amount of potential Cerulean Warbler habitat.

For each selected BBS route, land cover was collected within a 300-m buffer around each stop for aerial photos and the NLCD (Appendix 2). Cerulean Warblers rarely are detected beyond $100 \mathrm{~m}$ on point counts (Bosworth 2003), so the $300 \mathrm{~m}$ (28.3 ha) buffer is large enough to incorporate territories of Cerulean Warblers detected about $100 \mathrm{~m}$ from a stop. Several territories can occur within the $300 \mathrm{~m}$ buffer, as Oliarnyk and Robertson (1996) found Cerulean Warbler territories averaged 1.04 ha in size. Because 
aerial photos from different years and different programs have different resolutions, we digitized land cover by setting the view extent to the minimum scale available $(1: 60,000)$. For aerial photos, area was calculated for each polygon, and then summed for each land cover type per BBS stop. The NLCD was reclassified to the three land cover types and the area tabulated for each type around each stop. We used the percentage of each land cover type for analyses because the raster grid cells do not create a perfect circle around each of the route stops and as a result, the total area around each buffered stop varies slightly around 28.3 ha.

Change over time in several forest fragmentation metrics also was calculated for the aerial photo and NLCD datasets. Cerulean Warblers prefer large tracts of unfragmented deciduous forests (Hamel 2000b, Weakland and Wood 2005), so we included the metrics maximum size forest patch (ha) and forest core area (\%). We calculated the density of edge $(\mathrm{m} / \mathrm{ha})$ in each buffered stop for the aerial photo dataset. We examined the role of edge created by roads more closely in the NLCD dataset because of the frequent use of small, isolated canopy gaps and mid-sized gaps created by small roads and trails by Cerulean Warblers (Weakland and Wood 2005, Perkins 2006). We resampled the NLCD to a 10-m cell size to better represent the land cover surrounding small roads and trails than is done with the standard 30-m cell size. In the NLCD dataset, we calculated forest-forest edge density $(\mathrm{m} / \mathrm{ha})$ and forest-nonforest edge density $(\mathrm{m} / \mathrm{ha}$ ) because Cerulean Warblers may use gaps in forest created by the roads on BBS routes. Since roads were not included in the 1992 NLCD classification scheme (Vogelmann et al. 2001, Homer et al. 2004) and the 30-m cell size of the NLCD may not account for smaller roads, we accounted for the influence of roads by creating a several step process (see Appendix 3 for detailed methods) that incorporated a general roads layer in both NLCD datasets using U.S. Detailed Streets, part of StreetMap USA (http://www.esri.com/metatdata/esriprof80.dtd).

For the metrics maximum size forest patch, core forest, forest-forest edge density, and forest-nonforest edge density, the NLCD was reclassified as forest (sum of deciduous and mixed forest) and non-forest. Coniferous forest was not included because it is not considered to be suitable Cerulean Warbler habitat (Hamel 2000b). Maximum size forest patch was calculated for the largest deciduous/mixed polygon within the buffered area for 
the aerial photo and NLCD datasets. Mean core forest area was calculated with a $60-\mathrm{m}$ buffer (i.e., the area $>60 \mathrm{~m}$ from an edge) because edge effects are known to occur within $50 \mathrm{~m}$ of a forest edge (Paton 1994). Mean core forest was divided by the total area to obtain a percentage of core forest area in each buffer. The metric edge density, the amount of linear edge relative to the total land area of each buffered stop (McGarigal et al. 2002), was calculated using the four land cover classes for the aerial photo dataset. Since edge between deciduous/mixed forest and coniferous forest is not as striking a contrast for Cerulean Warblers as edge between deciduous/mixed forest and developed or composite land cover, we weighted a coniferous forest edge as zero and a developed or composite edge as one. Edge density was calculated using the Patch Analyst extension (Rempel et al. 2008) in ArcMap. For the NLCD dataset, forest-forest edge density is the amount of linear edge created by a road splitting deciduous/mixed forest patches. Forestnonforest edge density is the amount of linear edge between deciduous/mixed forest and non-forest patches (see Appendix 4 for detailed NLCD edge density methods).

Count data for Cerulean Warblers along the selected BBS routes were obtained from BBS staff at the USGS Patuxent Wildlife Research Center. Stop-level count data from 1997 onwards were downloaded from www.pwrc.usgs.gov/bbsapps/index.cfm. Earlier data were obtained by extracting from the field sheets the number of Cerulean Warblers detected at each stop along the selected routes. Cerulean Warbler detections were averaged within the 3-5 year time bracket surrounding each aerial photo or NLCD year.

Statistical Analyses. --- All statistical analyses were conducted using SAS (SAS Institute Inc. 2004) with $\alpha=0.10$. Univariate analyses determined that no variables were normally distributed, thus variables were transformed using the most appropriate method to achieve normality. We used an arcsine square root transformation on percent of each land cover type and percent forest core area, and a logarithmic transformation for maximum forest patch, edge density, forest-forest edge density, and forest-nonforest edge density. A square root transformation was applied to Cerulean Warbler average and maximum counts due to their poisson distribution (Zar 1996).

To examine long-term changes in habitat over the entire BBS survey period, we compared the four land cover classes (deciduous/mixed forest, coniferous forest, 
developed, composite) and three fragmentation metrics (maximum size forest patch, forest core area, edge density) measured for two routes from aerial photos for the early and middle time periods using analysis of variance (ANOVA; Ritchie et al. 1998). The ANOVA model included route, period, and stop within route. We also compared the land cover classes and fragmentation metrics in the middle and late time periods for six routes using ANOVA. We compared Cerulean Warbler detections for the two routes from the early and middle time periods and for the six routes from the middle and late time periods using analysis of covariance (ANCOVA; Welsh, Jr. and Ollivier 1998), with the variables route, period, and stop within route. The covariates were percentage of each land cover in each time period. Stop within route was the error term in the ANOVA and ANCOVA models for testing differences between the time periods. We repeated these comparisons between the middle and late time periods using only stops that had a Cerulean Warbler detected during one of the two periods.

We used ANOVA to compare changes from 1992 to 2001 in the proportion of three land cover classes (deciduous/mixed forest, coniferous forest, non-forest) and four fragmentation metrics (maximum size forest patch, interior forest, forest-forest edge density, forest-nonforest edge density) derived from NLCD data for 1,375 stops on 28 BBS routes. We also compared the land cover and fragmentation metrics between the 1992 and 2001 NLCD data, using only those stops where at least one Cerulean Warbler was detected (344 stops from 28 routes). We used the ANCOVA model and methods described above to compare Cerulean Warbler detections in each time period for all stops and for those at which the species was detected. The all stop analysis allows us to examine habitat changes across the landscape where Cerulean Warblers are known to occur, whereas the presence-only analysis allows us to examine the local conditions where Cerulean Warblers actually were detected.

As land cover changes, Cerulean Warbler detections may increase or decrease depending on which land cover type is changing. To more clearly evaluate this potential pattern, we grouped stops $(\mathrm{n}=1375)$ according to when Cerulean Warblers were detected: (1) detected in the years bracketing both the 1992 and 2001 NLCD, (2) detected in 1992 but not in 2001, (3) not detected in 1992 but detected in 2001, and (4) Cerulean Warblers not detected in either year. We compared the percent difference of each land cover 
category using NLCD data among the four Cerulean Warbler groups for 1,375 stops on $28 \mathrm{BBS}$ routes. We used an ANOVA model that included route, group, and a nested term of group within route. Group within route was used as the error term to account for variability among routes.

\section{RESULTS}

Aerial photo analysis for three time periods. ---Deciduous/mixed forest cover significantly increased from the early to middle time period along the two BBS routes (Table 1), whereas composite land cover significantly decreased. The amount of coniferous forest and developed land cover did not change, and none of the fragmentation metrics differed between the early and middle time periods. Along these routes, the average and maximum Cerulean Warbler counts significantly decreased from the early to middle period; Cerulean Warblers were detected at $15 \%$ of stops in the early period and at only $3 \%$ in the middle period.

Along the six BBS routes measured in the middle to late time period, there were no differences in deciduous/mixed and coniferous forest (Table 2). Developed land cover significantly increased and composite land cover significantly decreased. Core forest significantly increased from the middle to late time period, but maximum size forest patch and edge density did not change. Cerulean Warblers were detected at $18 \%$ of the stops for both the middle and late time period. Average Cerulean Warbler detections significantly decreased but the maximum number counted did not change from the middle to late time period.

Cerulean Warblers were detected at 76 stops along these routes during either the middle or late time period; 44 stops had Cerulean detections in both time periods. At stops where they were detected, developed land cover significantly increased, composite land cover type significantly decreased, and there was no change in deciduous/mixed or coniferous forest (Table 3). None of the fragmentation metrics differed between the middle and late time periods. Average Cerulean Warbler detections significantly decreased but the maximum number counted did not change significantly from the middle to late time period. 
NLCD analysis from 1992 to 2001. --- Along the 28 routes for which NLCD data were measured, significant changes occurred in all land cover and forest fragmentation metrics (Table 4; Appendix 5). The deciduous/mixed forest and coniferous forest land cover types significantly decreased, whereas the non-forest type increased significantly. The mean maximum size forest patch within a buffered stop significantly increased. Amount of core forest, forest-forest edge density, and forest-nonforest edge density all significantly decreased. Cerulean Warblers were detected at 14\% of stops in 1992 and $17 \%$ in 2001. Average and maximum Cerulean Warbler detections per stop did not change significantly, although counts increased slightly.

Cerulean Warblers were detected at 344 stops along these BBS routes (191 in 1992 and 231 in 2001). At these stops, coniferous and deciduous/mixed forests decreased significantly (Table 5), while non-forest land cover significantly increased from 15 to $25 \%$. For the forest fragmentation metrics, maximum size forest patch and forest-nonforest edge density significantly increased, whereas forest-forest edge density significantly decreased. There was no change in the amount of core forest. The mean and mean maximum number of Cerulean Warblers detected significantly increased in 2001.

In the analysis of land cover changes in BBS stops categorized by when Cerulean Warblers were detected, we found no relationship between a change in any of the land covers and change in Cerulean Warbler detections (Table 6).

\section{DISCUSSION}

Long-term habitat and Cerulean Warbler changes. --- Along the two BBS routes that provided adequate coverage for aerial photo analysis from two time periods, several land covers changed over time. The increase in deciduous/mixed forest and decline in the composite land cover type from the early to middle time period may be due to agricultural field abandonment and succession, similar to results found in other studies (Keller and Scallan 1999, Betts et al. 2007). The composite land cover type was dominated by agricultural land cover in this study. Many of these agricultural fields may have already been abandoned during the early time period, but the successional woody 
vegetation overtaking them was not established enough to be distinguishable from active agricultural fields. By the middle time period, sufficient time had elapsed for abandoned agricultural fields to develop into early stage forests that could be differentiated on aerial photos. Bart et al. (1995) also found an increase in forest cover from 1963 to 1988 within $280 \mathrm{~m}$ of roads in western Ohio.

If deciduous/mixed forest habitat was increasing, one might assume that an increase in Cerulean Warbler detections would follow. However, the mean and maximum detections at stops decreased from the early to middle period (Table 1) and they were detected at fewer stops. Similarly, regional analysis by Sauer et al. (2008) found Cerulean Warblers significantly declined from 1967-1982 along 43 of the 54 routes surveyed in two of the three physiographic areas that comprise the study area (Table 7). Although field abandonment and succession may have created more deciduous/mixed forest, these forests were likely not yet suitable Cerulean Warbler habitat. These young forests would consist mainly of shrubs and pole-sized trees, lacking the large mature trees (Hamel 2000a) and horizontal and vertical structural diversity that Cerulean Warblers prefer (Weakland and Wood 2005, Perkins 2006). No change in any of the fragmentation metrics suggests there may be other microhabitat features that are influencing habitat suitability and population trends for Cerulean Warbler.

From the middle to late period along six BBS routes, land cover lost from the composite type was replaced by developed land cover for all stops and the presence-only stops. Agricultural fields that dominate this land cover category may have been converted into some type of development instead of being abandoned during this time period. Although there was no change in deciduous/mixed forest, core forest increased over time in the all stops dataset. If agricultural field abandonment occurred at a similar rate along the BBS routes that we were not able to interpret with aerial photos in the early time period, it is possible that the early stage deciduous/mixed forests developed a more contiguous canopy cover from the middle to late time period. Although, core forest has been considered to be an important habitat characteristic for Cerulean Warblers (Hamel 2000b, Oliarnyk 1996), Cerulean Warbler detections decreased over time. Cerulean Warblers were detected at $18 \%$ of all stops and $58 \%$ of presence-only stops for both the middle and late time period, however, there were more detected per stop in the middle 
than the late time period (Tables 2, 3). Regionally, Sauer et al. (2008) found similar results; Cerulean Warblers declined along 50 of 85 routes surveyed in one of the three physiographic areas within our study area (Ohio Hills, Table 7) from 1982-2003. In the presence-only analysis, the lack of a change in fragmentation metrics that are believed to be important to Cerulean Warblers, such as interior, unfragmented deciduous forest (Hamel 2000b, Oliarnyk 1996), suggests that there may be other factors influencing the population trends of Cerulean Warblers. It is also possible that events or conditions during migration or on the wintering grounds may be contributing to population declines. For example, in the lower elevations of the Andes and other mountains in northern South America, where Cerulean Warblers winter, forested habitat is being converted to pastures, and cacao and coffee plantations (Hamel 2000a, Hamel 2000b). Research is only beginning to examine the effects of this habitat loss on Cerulean Warblers (Bakermans 2008).

Recent short-term habitat and Cerulean Warbler changes.--- Several land cover variables believed to be important to Cerulean Warblers declined from 1992 to 2001 along BBS stops. The land cover lost from deciduous/mixed forest was mainly replaced by non-forest land cover (Tables 4 and 5). Non-forest land cover along these routes primarily consists of developed and agricultural land. The conversion of deciduous/mixed forests to non-forest is due to development, which occurs more frequently near than away from roads (Chomitz and Gray 1996). The rural, secondary nature of BBS roads make them likely targets of land cover change as human populations and needs continue to expand. The amount of deciduous/mixed forest and core forest was greater at presence-only stops compared to all stops. Despite the decline in deciduous/mixed forest, Cerulean Warbler detections increased at presence-only stops and did not change at all stops over time. This suggests that there may be more important microhabitat features that Cerulean Warblers key in on than simply large, continuous deciduous/mixed forests. Further, the decline in the forest-forest edge density and increase in forest-nonforest edge density suggests that local and regional land cover surrounding BBS stops is becoming increasingly fragmented. A key habitat factor for Cerulean Warblers includes interior, unfragmented forests (Hamel 2000b, Oliarnyk 1996) 
however there was already little interior forest (10\% for all stops and $13 \%$ for presenceonly stops) in 1992 within 300 m of BBS stops.

Despite the decline in amount of deciduous/mixed forests and core forests, Cerulean Warbler detections did not change significantly between 1992 and 2001 at a landscape scale across all BBS stops examined (Table 4). Cerulean Warblers were detected at 14\% of all stops in 1992 and 17\% in 2001; however, Sauer et al. (2008) reported significant declines during this time period for each of the three physiographic areas intersecting the study area (Table 7). The lack of a decline in Cerulean Warblers detected for BBS stops included in our study may relate to which routes we could include. We were only able to include $28 \mathrm{BBS}$ routes because of constraints from lack of stop-level coordinates and routes run inconsistently, while the Cerulean Warbler BBS trends in Table 7 are based on 75 routes. Also, our study area focused on the core breeding range of Cerulean Warblers, whereas the physiographic area analyses included BBS routes near the periphery of the Cerulean Warbler's range (Fig. 1), such as southern Tennessee and parts of Alabama and Georgia in the Northern Cumberland Mountains and the Virginia section of the Mid Atlantic Ridge and Valley physiographic areas, where they may be declining at a faster rate.

Another possibility for no change in Cerulean Warbler detections in our study is that even though habitat along the studied BBS routes is declining, there may still be sufficient habitat to support stable abundances of Cerulean Warblers over time. Mean territory size has been found to range from 0.21 ha (Roth 2004) to 1.04 ha (Oliarnyk and Robertson 1996). The maximum size forest patches increased for both all stops and presence-only stops within $300 \mathrm{~m}$ of a BBS stop in our study area (Table 4 and 5), and were large enough to contain several Cerulean Warbler territories. This suggests there may be fine-scale microhabitat changes that we were unable to detect with our coarse land cover analysis, such as small, isolated canopy gaps (Perkins 2006). Despite the decrease in forest-forest edge density and increase in forest-nonforest edge density, Cerulean Warblers detections increased over time in the presence-only analysis, providing support that at a local scale Cerulean Warblers are able to tolerate some degree of edge habitat which may increase the structural and vertical diversity in the canopy. In 
addition, the smaller amount of non-forest land cover along presence-only stops supports Cerulean Warbler avoidance of large-scale disturbance (Wood et al. 2006).

\section{CONCLUSIONS}

Several key aspects of this study provide additional information to the growing body of research into the conservation efforts of Cerulean Warblers. To our knowledge, this is the first study to analyze changes over time in bird abundance and land cover at BBS stops rather than at the route-level. Many important changes may be occurring within the $40 \mathrm{~km}$ route at a scale too small for route-level analyses to detect. Also, as remote sensing technology continues to improve, such as the development of Light Detection and Ranging (LIDAR), land cover analysis will improve, increasing the potential to measure microhabitat features such as canopy gaps (Wulder et al. 2007). As coordinates are collected for stops along more BBS routes (with help from BBS observers who regularly run routes and collect stop coordinates), a goal of the BBS office (K. Pardieck, pers. comm.), more complete analysis of habitat factors influencing stoplevel trends in Cerulean Warbler detection will be possible. Finally, the data collected and methodology used in this study can also be used for additional bird species of conservation concern, such as the Wood Thrush (Hylocichla mustelina).

This study also illustrates the potential importance of microhabitat features for Cerulean Warbler habitat selection. In the NLCD analyses at the local scale (i.e., at stops where one or more Cerulean Warbler were present), broad habitat features such as deciduous/mixed forest and forest-forest edge density decreased significantly over time , while Cerulean Warbler detections increased. However, none of the habitat variables analyzed measure canopy gaps, which provide vertical and structural diversity within the canopy that Cerulean Warblers seem to prefer. Cerulean Warblers seem to be able to tolerate a degree of edge habitat, but more research into what amount of edge increases the habitat suitability for Cerulean Warblers will further our knowledge of the habitat preferences of this species and provide guidance to refine habitat recommendations. As research on Cerulean Warblers continues, the role of microhabitat features will increase the understanding about the causes of Cerulean Warbler population declines. 


\section{LITERATURE CITED}

Bakermans, M. H. 2008. Demography and habitat use of Cerulean Warblers on breeding and wintering grounds. Dissertation. The Ohio State University, Columbus, USA.

Bart, J., M. Hofschein, and B. G. Peterjohn. 1995. Reliability of the Breeding Bird Survey: effects of restricting surveys to roads. The Auk 112:758-761.

Betts, M. G., D. Mitchell, A. W. Diamond, and J. Bety. 2007. Uneven rates of landscape change as a source of bias in roadside wildlife surveys. Journal of Wildlife Management 71: 2266-2273.

Bosworth, S. B. 2003. Cerulean Warbler relative abundance and frequency of occurrence relative to large-scale edge. Thesis. West Virginia University, Morgantown, USA.

Chomitz, K. M. and D. A. Gray. 1996. Roads, land use, and deforestation: a spatial model applied to Belize. World Bank Economic Review 10: 487-512.

Demarest, D. 2003. Northern Cumberland Plateau, Physiographic Area 21-Executive Summary. Partners in Flight. www.partnersinflight.org/bcps/pl_21sum.htm (accessed 29 September 2008).

Donovan, T. M. and C. H. Flather. 2002. Relationships among North American songbird trends, habitat fragmentation, and landscape occupancy. Ecological Applications 12: 364-374.

Federal Register. 2006. Endangered and Threatened Wildlife and Plants; 12-month finding on a petition to list the Cerulean Warbler (Dendroica cerulea) as threatened with critical habitat. 71: 70717-70733.

Hamel, P. B. 2000a. Cerulean Warbler status assessment. U.S. Fish and Wildlife Service. www.fws.gov/Midwest/eco_serv/soc/birds/cerw/cewa_sa.html (accessed 1 September 2008).

Hamel, P. B. 2000b. Cerulean Warbler (Dendroica cerulea). In The Birds of North America, No. 511 (A. Poole and F. Gill, Editors.). The Birds of North America, Inc., Philadelphia, Pennsylvania, USA.

Hamel, P. B., D. K. Dawson, and P. D. Keyser. 2004. How we can learn more about the Cerulean Warbler (Dendroica cerulea). Auk 121: 7-14.

Homer, C., C. Huang, L. Yang, B. Wylie, and M. Coan. 2004. Development of a 2001 National Land-Cover Database for the United States. Photogrammetric Engineering and Remote Sensing 70: 829-840. 
Keller, C. M. E. and J. T. Scallan. 1999. Potential roadside biases due to habitat changes along Breeding Bird Survey routes. Condor 101: 50-57.

McGarigal, K., S. A. Cushman, M. C. Neel, and E. Ene. 2002. FRAGSTATS: spatial pattern analysis program for categorical maps. Computer software program produced by the authors at the University of Massachusetts, Amherst, USA. www.umass.edu/landeco/research/fragstats/fragstats.html. (accessed 17 Dec 2008).

National Land Cover Dataset (NLCD). 2007. U.S. Environmental Protection Agency. National Land Cover Dataset Metadata. www.epa.gov/esd/uwr_browser/pages/uwr_metadata_nlcd.htm. (accessed 5 March 2009).

North American Breeding Bird Survey. 2001. USGS Patuxent Wildlife Research Center About BBS. www.pwrc.usgs.gov/BBS/about/. (accessed 4 March 2009).

O'Connor, R. J., E. Dunn, D. H. Johnson, S. L. Jones, D. Petit, K. Pollock, C. R. Smith, J. L. Trapp, and E. Welling. 2000. A programmatic review of the North American Breeding Bird Survey. Report of a peer review panel. Patuxent Wildlife Research Center, Laurel, Maryland. www.pwrc.usgs.gov/BBS/bbsreview/bbsfinal.pdf (accessed 20 April 20 2009).

Oliarnyk, C. J. 1996. Habitat selection and reproductive success in a population of Cerulean Warblers in southeastern Ontario. M.S. Thesis, Queen's University, Kingston, Ontario, Canada.

Oliarnyk, C. J. and R. J. Robertson. 1996. Breeding behavior and reproductive success of Cerulean Warblers in southeastern Ontario. Wilson Bulletin 108: 673-684.

Pashley, D. N., C. J. Beardmore, J. A. Fitzgerald, R. P. Ford, W. C. Hunter, M. S. Morrison, and K. V. Rosenberg. 2000. Partners In Flight: Conservation of the land birds of the United States. American Bird Conservancy, The Plains, Virginia, USA.

Paton, P. W. C. 1994. The effect of edge on avian nest success: how strong is the evidence? Conservation Biology 8: 17-26.

Perkins, K. A. 2006. Cerulean Warbler selection of forest canopy gaps. Thesis. West Virginia University, Morgantown, USA.

Rempel, R. S., A. P. Carr, and D. Kaukinen. 2008. Patch analyst extension for ArcMap: Version 4.0. http://flash.lakeheadu.ca/ rrempel/patch/ (accessed 15 October 2008).

Ritchie, M. E., D. Tilman, and J. M. H. Knops. 1998. Herbivore effects on plants and nitrogen dynamics in oak savanna. Ecology 79: 165-177.

Rosenberg, K. 1999. Mid-Atlantic Ridge and Valley, Physiographic Area 12-Executive Summary. Partners in Flight. www.partnersinflight.org/bcps/pl_12sum.htm (accessed 29 September 2008). 
Rosenberg, K. 2000. Ohio Hills, Physiographic Area 22-Executive Summary. Partner in Flight. www.partnersinflight.org/bcps/pl_22sum.htm (accessed 29 September 2008).

Rosenberg, K. V., S. E. Barker, and R. W. Rohrbaugh. 2000. An atlas of Cerulean Warbler Populations-Final Report to the USFWS: 1997-2000 Breeding Seasons. Cornell Laboratory of Ornithology, Ithaca, New York.

Roth, K. L. 2004 Cerulean Warbler breeding biology in Big Oaks National Wildlife Refuge, Madison, IN. Thesis. Ball State University, Muncie, USA.

SAS Institute Inc. 2004. SAS software. version 9.1. SAS Institute Inc., Cary, North Carolina, USA.

Sauer, J. R. 1999. Combining information from monitoring programs: complications associated with indices and geographic scale. In Strategies for bird conservation: The Partners in Flight planning process (R. Bonney, D.N. Pashley, R.J. Cooper, and L. Niles, eds.). Cornell Lab of Ornithology.

Sauer, J. R., J. E. Hines, and J. Fallon. 2008. The North American Breeding Bird Survey, results and analyses 1966-2007. version 5.15.2008. USGS Patuxent Wildlife Research Center, Laurel, Maryland. www.mbr-pwrc.usgs.gov/bbs/bbs.html (accessed 18 July 2008).

Thogmartin, W. E., A. L. Gallant, M. G. Knutson, T. J. Fox, and M. J. Suarez. 2004. Commentary: A cautionary tale regarding use of the National Land Cover Dataset 1992. Wildlife Society Bulletin 32: 970-978.

Vogelmann, J. E., S. M. Howard, and C. R. Larson. 2001. Completion of the 1990s National Land Cover Data set for the conterminous United State from Landsat Thematic Mapper data and ancillary data sources. Photogrammetric Engineering and Remote Sensing. 67: 650-662.

Weakland, C. A. and P. B. Wood. 2005. Cerulean Warbler (Dendroica cerulea) microhabitat and landscape-level habitat characteristics in southern West Virginia. Auk 122: 497-508.

Welsh, Jr., H. H. and L. M. Ollivier. 1998. Stream amphibians as indicators of ecosystem stress: a case study from California's redwoods. Ecological Applications 8: 11181132.

Wickham, J. D. K. H. Riitters, T. G. Wade, M. Coan, and C. Homer. 2007. The effects of Appalachian mountaintop mining on interior forest. Landscape Ecology 22: 179-187.

Wood, P. B., S. Bosworth, and R. Dettmers. 2006. Cerulean Warbler abundance and occurrence relative to large-scale edge and habitat characteristics. Condor 108:154165. 
Wood, P. B., J. P. Duguay, and J. V. Nichols. 2005 Cerulean Warbler use of regenerated clearcut and two-age harvests. Wildlife Society Bulletin 33: 851-858.

Wulder, M. A., T. Han, J. C. White, T. Sweda, and H. Tsuzuki. 2007. Integrating profiling LIDAR with Landsat data for regional boreal forest canopy attribute estimation and change characterization. Remote Sensing of Environment 110: 123137.

Zar, J. H. 1996. Biostatistical analysis, $3^{\text {rd }}$ Edition. Prentice Hall, Upper Saddle River, New Jersey, USA. 
TABLE 1. Land cover and fragmentation metrics based on aerial photographs for the early (1967/1971) and middle (1982) time periods and Cerulean Warbler detections during a five year bracket surrounding each aerial photo year for 68 stops on two BBS routes.

\begin{tabular}{|c|c|c|c|c|c|c|c|c|}
\hline & \multicolumn{3}{|c|}{ Early } & \multicolumn{3}{|c|}{ Middle } & \multirow{2}{*}{$\begin{array}{c}F- \\
\text { value }\end{array}$} & \multirow{2}{*}{$\begin{array}{l}P- \\
\text { value }\end{array}$} \\
\hline & Mean & SE & Range & Mean & SE & Range & & \\
\hline \multicolumn{9}{|l|}{ Landcover (\%) } \\
\hline Deciduous/mixed forest & 36.3 & 3.1 & $0-100$ & 49.3 & 3.4 & $0-100$ & 3.82 & 0.055 \\
\hline Coniferous forest & 1.5 & 0.6 & $0-21.7$ & 2.3 & 1.15 & $0-60.2$ & 0 & 0.98 \\
\hline Developed & 16.8 & 2.4 & $0-73.9$ & 14.7 & 2.11 & $0-82.8$ & 0.32 & 0.57 \\
\hline Composite & 45.4 & 3.1 & $0-96.3$ & 33.9 & 3.16 & $0-100$ & 5.3 & 0.024 \\
\hline \multicolumn{9}{|l|}{ Fragmentation metrics } \\
\hline Max. forest patch (ha) & 6.8 & 0.6 & $0-17.0$ & 8.8 & 0.6 & $0-17.5$ & 1.10 & 0.30 \\
\hline Core forest $(\%)$ & 7.8 & 1.2 & $0-43.7$ & 10.6 & 1.8 & $0-69.7$ & 0.68 & 0.41 \\
\hline Edge density (m/ha) & 138.6 & 5.3 & $.9-233.7$ & 136.8 & 4.6 & $42.1-403.2$ & 0 & 0.99 \\
\hline \multicolumn{9}{|l|}{ Cerulean Warblers } \\
\hline Average & 0.05 & 0.02 & $0-0.50$ & 0.01 & 0.007 & $0-0.33$ & 5.25 & 0.025 \\
\hline Maximum & 0.16 & 0.05 & $0-2.0$ & 0.03 & 0.02 & $0-1.0$ & 5.48 & 0.022 \\
\hline
\end{tabular}


TABLE 2. Land cover and fragmentation metrics based on aerial photographs for the middle (1982/1985) and late (2000/2003) time periods and Cerulean Warbler detections during a five year bracket surrounding each aerial photo year for 240 stops on six BBS routes.

\begin{tabular}{|c|c|c|c|c|c|c|c|c|}
\hline & \multicolumn{3}{|c|}{ Middle } & \multicolumn{3}{|c|}{ Late } & \multirow{2}{*}{$\begin{array}{l}F- \\
\text { value }\end{array}$} & \multirow{2}{*}{$\begin{array}{l}P- \\
\text { value }\end{array}$} \\
\hline & Mean & SE & Range & Mean & SE & Range & & \\
\hline \multicolumn{9}{|l|}{ Landcover (\%) } \\
\hline Deciduous/mixed forest & 58.9 & 1.7 & $0-100$ & 62.0 & 1.6 & $0-100$ & 0.97 & 0.32 \\
\hline Coniferous forest & 1.0 & 0.4 & $0-60.2$ & 0.8 & 0.3 & $0-39.0$ & 0.16 & 0.69 \\
\hline Developed & 9.7 & 1.0 & $0-89.9$ & 14.7 & 1.4 & $0-92.9$ & 9.4 & 0.002 \\
\hline Composite & 30.5 & 1.6 & $0-100$ & 22.5 & 1.4 & $0-96.6$ & 9.88 & 0.002 \\
\hline \multicolumn{9}{|l|}{ Fragmentation metrics } \\
\hline Max. forest patch (ha) & 13.4 & 0.3 & $0-25.1$ & 10.4 & 0.3 & $0-26.1$ & 2.5 & 0.12 \\
\hline Core forest (\%) & 14.8 & 0.9 & $0-69.7$ & 16.6 & 0.8 & $0-43.9$ & 2.96 & 0.087 \\
\hline Edge density (m/ha) & 142.1 & 3.0 & $42.1-403.2$ & 144.8 & 3.3 & $33.2-273.9$ & 0.08 & 0.77 \\
\hline \multicolumn{9}{|l|}{ Cerulean Warblers } \\
\hline Average & 0.09 & 0.02 & $0-1.67$ & 0.06 & 0.01 & $0-1.0$ & 4.6 & 0.033 \\
\hline Maximum & 0.23 & 0.03 & $0-3.0$ & 0.21 & 0.03 & $0-2.0$ & 1.07 & 0.30 \\
\hline
\end{tabular}


TABLE 3. Land cover and fragmentation metrics based on aerial photographs for the middle (1982/1985) and late (2000/2003) time periods and Cerulean Warbler detections during a five year bracket surrounding each aerial photo year for 76 presence-only stops on six BBS routes.

\begin{tabular}{|c|c|c|c|c|c|c|c|c|}
\hline & \multicolumn{3}{|c|}{ Middle } & \multicolumn{3}{|c|}{ Late } & \multirow{2}{*}{$\begin{array}{l}F- \\
\text { value }\end{array}$} & \multirow{2}{*}{$\begin{array}{c}P- \\
\text { Value }\end{array}$} \\
\hline & Mean & $\mathrm{SE}$ & Range & Mean & $\mathrm{SE}$ & Range & & \\
\hline \multicolumn{9}{|l|}{$\overline{\text { Landcover (\%) }}$} \\
\hline Deciduous/mixed forest & 69.9 & 2.5 & $0-100$ & 74.4 & 2.1 & $9.2-100$ & 0.73 & 0.39 \\
\hline Coniferous forest & 1.1 & 0.6 & $0-41.1$ & 0.7 & 0.6 & $0-39.0$ & 0.92 & 0.34 \\
\hline Developed & 5.4 & 1.2 & $0-48.5$ & 8.6 & 1.4 & $0-58.4$ & 5.08 & 0.027 \\
\hline Composite & 23.7 & 2.2 & $0-93.1$ & 16.3 & 1.8 & $0-69.4$ & 4.28 & 0.042 \\
\hline \multicolumn{9}{|l|}{ Fragmentation metrics } \\
\hline Max. forest patch (ha) & 11.2 & 0.5 & $0-25.1$ & 12.0 & 0.5 & $2.6-26.1$ & 1.33 & 0.25 \\
\hline Core forest $(\%)$ & 18.9 & 1.4 & $0-43.4$ & 20.9 & 1.3 & $0-43.9$ & 0.92 & 0.34 \\
\hline Edge density $(\mathrm{m} / \mathrm{ha})$ & 139.9 & 5.6 & $43.3-262.6$ & 139.3 & 6.1 & $33.2-256.5$ & 0.04 & 0.85 \\
\hline \multicolumn{9}{|l|}{ Cerulean Warblers } \\
\hline Average & 0.28 & 0.04 & $0-1.67$ & 0.19 & 0.02 & $0-1.0$ & 7.77 & 0.007 \\
\hline Maximum & 0.71 & 0.08 & $0-3.00$ & 0.67 & 0.07 & $0-2.0$ & 2.7 & 0.10 \\
\hline
\end{tabular}


TABLE 4. Land cover and fragmentation metrics based on 1992 and 2001 NLCD and Cerulean Warbler detections during 1990-1994 and 1999-2003 for 1,375 stops on 28 BBS routes. $($ FF edge density $=$ Forest-forest edge density, FNF edge density $=$ Forestnonforest edge density).

\begin{tabular}{|c|c|c|c|c|c|c|c|c|}
\hline & \multicolumn{3}{|c|}{1992} & \multicolumn{3}{|c|}{2001} & \multirow{2}{*}{$\begin{array}{c}F- \\
\text { value }\end{array}$} & \multirow{2}{*}{$\begin{array}{c}P- \\
\text { value }\end{array}$} \\
\hline & Mean & SE & Range & Mean & $\mathrm{SE}$ & Range & & \\
\hline \multicolumn{9}{|l|}{ Landcover $(\%)$} \\
\hline Deciduous/Mixed forest & 64.3 & 0.8 & $0-100$ & 59.4 & 0.7 & $0-98.1$ & 38.94 & $<0.001$ \\
\hline Coniferous forest & 3.3 & 0.2 & $0-62$ & 1.5 & 0.1 & $0-66.1$ & 161.09 & $<0.001$ \\
\hline Non-forest & 32.4 & 0.8 & $0-100$ & 39.1 & 0.7 & $1.9-100$ & 79.08 & $<0.001$ \\
\hline \multicolumn{9}{|l|}{ Fragmentation metrics } \\
\hline Max. forest patch (ha) & 7.6 & 0.1 & $0-18$ & 8.0 & 0.1 & $0--21.4$ & 7.2 & 0.007 \\
\hline Core forest $(\%)$ & 9.7 & 0.3 & $0-38.2$ & 9.1 & 0.3 & $0-44.3$ & 10.99 & 0.001 \\
\hline FF edge density (m/ha) & 20.5 & 0.4 & $0-103.5$ & 7.5 & 0.2 & $0-37.4$ & 423.04 & $<0.001$ \\
\hline FNF edge density $(\mathrm{m} / \mathrm{ha})$ & 187.8 & 2.8 & $0-496.9$ & 172.9 & 1.8 & $0-410.1$ & 11.34 & 0.001 \\
\hline \multicolumn{9}{|l|}{ Cerulean Warbler } \\
\hline Average & 0.08 & 0.01 & $0-3.3$ & 0.1 & 0.01 & $0-3.00$ & 2.54 & 0.11 \\
\hline Maximum & 0.19 & 0.01 & $0-6.00$ & 0.25 & 0.02 & $0-5.00$ & 1.81 & 0.18 \\
\hline
\end{tabular}


TABLE 5. Land cover and fragmentation metrics based on 1992 and 2001 NLCD and Cerulean Warbler detections from 1990-1994 and 1999-2003 for 344 presence-only stops along 28 BBS routes. (FF edge density $=$ Forest-forest edge density, FNF edge density $=$ Forest-nonforest edge density).

\begin{tabular}{|c|c|c|c|c|c|c|c|c|}
\hline & \multicolumn{3}{|c|}{1992} & \multicolumn{3}{|c|}{2001} & \multirow{2}{*}{$\begin{array}{r}F- \\
\text { value }\end{array}$} & \multirow{2}{*}{$\begin{array}{r}P- \\
\text { value }\end{array}$} \\
\hline & Mean & SE & Range & Mean & SE & Range & & \\
\hline \multicolumn{9}{|l|}{ Landcover $(\%)$} \\
\hline Deciduous/Mixed forest & 81.6 & 1.0 & $10.3-100$ & 74.4 & 0.8 & $17.9-95.2$ & 45.88 & $<0.001$ \\
\hline Coniferous forest & 3.8 & 0.3 & $0-44.3$ & 0.9 & 0.2 & $0-54.8$ & 125.09 & $<0.001$ \\
\hline Non-forest & 14.6 & 1.0 & $0-89.7$ & 24.8 & 0.8 & $4.8-81.7$ & 110.07 & $<0.001$ \\
\hline \multicolumn{9}{|l|}{ Fragmentation metrics } \\
\hline Max. forest patch (ha) & 9.0 & 0.2 & $1.8-17.9$ & 9.7 & 0.2 & $1.2-18.5$ & 3.49 & 0.0626 \\
\hline Core forest $(\%)$ & 13.4 & 0.5 & $0-38.2$ & 13.5 & 0.6 & $0-43.8$ & 0.15 & 0.6983 \\
\hline FF edge density (m/ha) & 25.8 & 0.7 & $0.6-84.7$ & 9.2 & 0.4 & $0-37.0$ & 255.08 & $<0.001$ \\
\hline FNF edge density $(\mathrm{m} / \mathrm{ha})$ & 159.9 & 5.7 & $0-483.4$ & 179.1 & 3.2 & $87.9-410.1$ & 54.24 & $<0.001$ \\
\hline \multicolumn{9}{|l|}{ Cerulean Warblers } \\
\hline Average & 0.31 & 0.03 & $0-3.33$ & 0.41 & 0.03 & $0-3.0$ & 5.45 & 0.025 \\
\hline Maximum & 0.76 & 0.05 & $0-6.0$ & 0.99 & 0.05 & $0-5.0$ & 5.6 & 0.018 \\
\hline
\end{tabular}


TABLE 6. Influence of percent change in land cover on Cerulean Warblers when grouped by detection from 1992-2001 $(n=1,375)$. Cerulean Warblers are in four groups: (1) detected in 1992 and 2001 (78 stops); (2) detected in 1992, but not in 2001 (113 stops); (3) not detected in 1992, but detected in 2001 (152 stops); (4) not detected in 1992 or 2001 (1032 stops). A (+) percent change means more of that land cover was detected in 2001, a (-) percent change means more of that land cover was detected in 1992.

\begin{tabular}{|c|c|c|c|c|c|c|c|c|c|c|}
\hline \multirow[b]{2}{*}{ Landcover } & \multicolumn{2}{|c|}{ Group 1} & \multicolumn{2}{|c|}{ Group 2} & \multicolumn{2}{|c|}{ Group 3} & \multicolumn{2}{|c|}{ Group 4} & \multicolumn{2}{|c|}{ Group (route) } \\
\hline & Mean & $\mathrm{SE}$ & Mean & $\overline{\mathrm{SE}}$ & Mean & $\overline{\mathrm{SE}}$ & Mean & $\overline{\mathrm{SE}}$ & $F$-value & $P$-value \\
\hline \multicolumn{11}{|l|}{ Deciduous/Mixed } \\
\hline forest & -8.38 & 1.22 & -4.00 & 0.78 & -9.05 & 1.09 & -4.05 & 0.40 & 0.19 & 0.90 \\
\hline Coniferous forest & -1.45 & 0.30 & -1.84 & 0.45 & -4.58 & 0.45 & -1.46 & 0.14 & 0.10 & 0.96 \\
\hline Non-forest & 9.84 & 1.15 & 5.84 & 0.75 & 13.63 & 1.24 & 5.50 & 0.39 & 0.16 & 0.92 \\
\hline
\end{tabular}


TABLE 7. Route-level Cerulean Warbler population trends for each Partners In Flight (PIF) physiographic area intersecting the study area (Sauer et al. 2008).

\begin{tabular}{lrrrrr}
\hline \multicolumn{1}{c}{ PIF area } & Routes & Trend (\%) & Variance & $P$-value & $\begin{array}{r}\text { Average count } \\
\text { per route }\end{array}$ \\
\hline $1967-1982$ & & & & & 0.903 \\
Ohio Hills & 31 & -4.85 & 2.19 & 0.93 \\
Cumberland Plateau & 12 & -5.19 & 5.50 & 0.058 & 2.08 \\
Ridge and Valley & 11 & 1.02 & 21.93 & 0.84 & 0.22 \\
& & & & & \\
1982-2003 & & & & & 2.38 \\
Ohio Hills & 50 & -2.23 & 0.93 & 0.025 & 2.62 \\
Cumberland Plateau & 16 & -2.05 & 2.83 & 0.25 & 0.15 \\
Ridge and Valley & 19 & -0.36 & 9.31 & 0.91 & \\
& & & & & 2.49 \\
1992-2001 & & & & & 0.24 \\
Ohio Hills & 45 & -6.79 & 0.65 & $<0.001$ & \\
Cumberland Plateau & 15 & -4.06 & 4.85 & 0.092 & \\
Ridge and Valley & 15 & -6.70 & 2.39 & 0.001 & \\
\hline
\end{tabular}




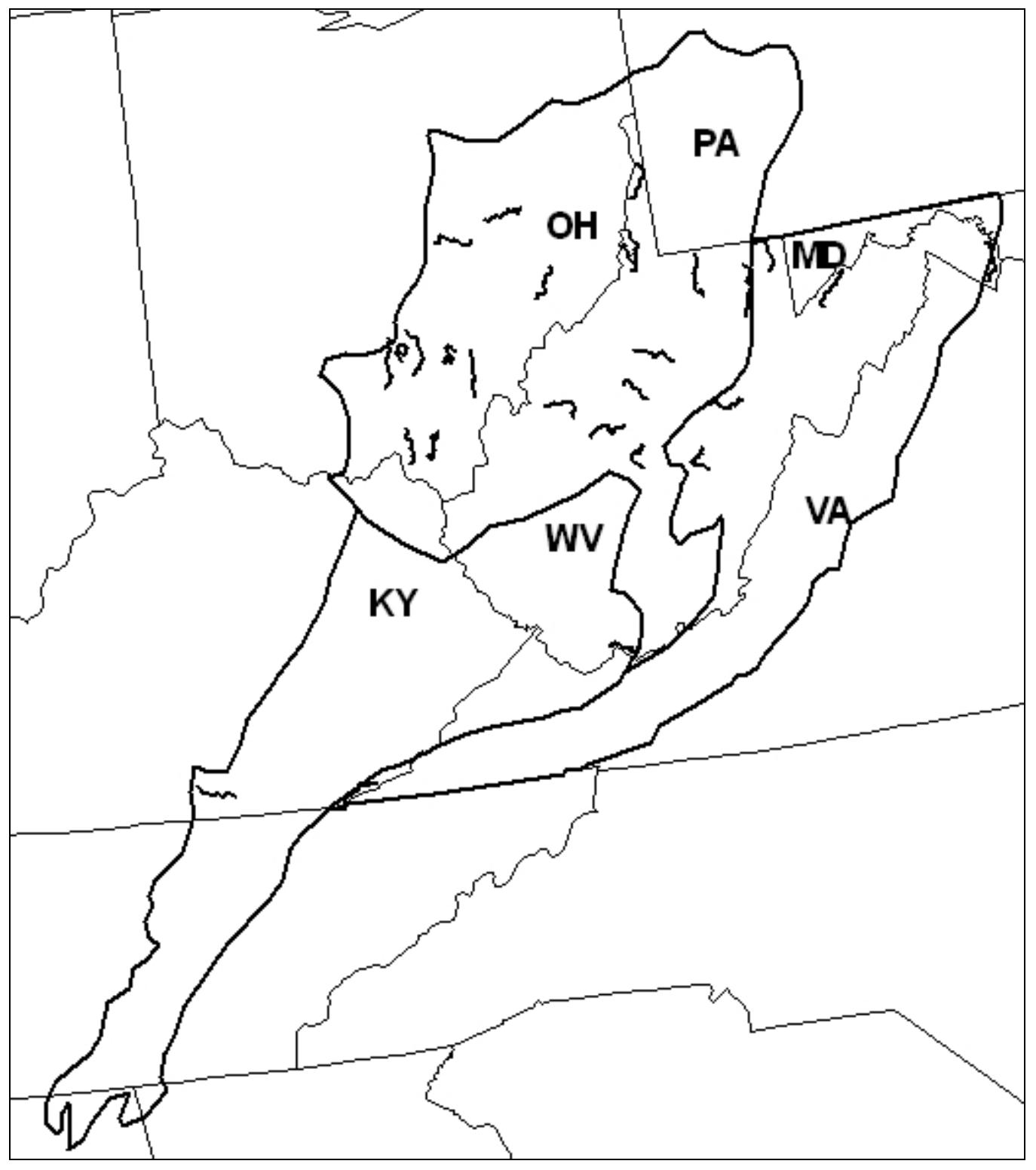

FIG. 1. Study area in West Virginia, Kentucky, and Ohio portions of Partners In Flight physiographic regions Ohio Hills, N. Cumberland Plateau, and Mid Atlantic Ridge and Valley (heavy outline) with location of 28 BBS routes with stop-level coordinates analyzed in this study. 
APPENDIX 1. Aerial photo metadata for six BBS routes.

\begin{tabular}{|c|c|c|c|c|c|c|c|c|}
\hline \multirow[b]{2}{*}{ State } & \multicolumn{8}{|l|}{ BBS } \\
\hline & Route & Name & Period & Year & County(ies) & Program & Datum & Scale \\
\hline West & 90024 & Three Forks & Middle & 1985 & Webster & NHAP1 & NAD 83 & $1: 60000$ \\
\hline \multirow[t]{17}{*}{ Virginia } & & & Late & 2003 & & WV SAMB & NAD 83 & 1:4800 \\
\hline & 90026 & Cedarville & Middle & 1985 & Gilmer & NHAP1 & NAD 83 & 1:60000 \\
\hline & & & Late & 2003 & & WV SAMB & NAD 83 & $1: 4800$ \\
\hline & 90037 & Moundsville & Middle & 1982 & Marshall & NHAP1 & NAD 83 & $1: 60000$ \\
\hline & & & Late & 2003 & & WV SAMB & NAD 83 & $1: 4800$ \\
\hline & & & Middle & 1982 & Wetzel & NHAP1 & NAD 83 & 1:60000 \\
\hline & & & Late & 2003 & & WV SAMB & NAD 83 & $1: 4800$ \\
\hline & 90038 & Monongah & Early & 1967 & Monongalia & FSA & NAD 83 & 1:20000 \\
\hline & & & Middle & 1982 & & NHAP1 & NAD 83 & 1:60000 \\
\hline & & & Late & 2003 & & WV SAMB & NAD 83 & $1: 4800$ \\
\hline & & & Early & 1967 & Marion & FSA & NAD 83 & $1: 20000$ \\
\hline & & & Middle & 1982 & & NHAP1 & NAD 83 & 1:60000 \\
\hline & & & Late & 2003 & & WV SAMB & NAD 83 & $1: 4800$ \\
\hline & 90041 & Bebee & Middle & 1982 & Marshall & NHAP1 & NAD 83 & $1: 60000$ \\
\hline & & & Late & 2003 & & WV SAMB & NAD 83 & $1: 4800$ \\
\hline & & & Middle & 1982 & Wetzel & NHAP1 & NAD 83 & $1: 60000$ \\
\hline & & & Late & 2003 & & WV SAMB & NAD 83 & $1: 4800$ \\
\hline \multirow[t]{9}{*}{ Ohio } & 66049 & Dresden & Early & 1971 & Muskingum & FSA & NAD 83 & 1:20000 \\
\hline & & & Middle & 1982 & & NHAP1 & NAD 83 & $1: 60000$ \\
\hline & & & Late & 2000 & & NAPP3 & NAD 83 & $1: 40000$ \\
\hline & & & Early & 1971 & Conshocton & FSA & NAD 83 & $1: 20000$ \\
\hline & & & Middle & 1982 & & NHAP1 & NAD 83 & 1:60000 \\
\hline & & & Late & 2000 & & NAPP3 & NAD 83 & $1: 40000$ \\
\hline & & & Early & 1971 & Guernsey & FSA & NAD 83 & $1: 20000$ \\
\hline & & & Middle & 1982 & & NHAP1 & NAD 83 & 1:60000 \\
\hline & & & Late & 2000 & & NAPP3 & NAD 83 & $1: 40000$ \\
\hline
\end{tabular}


APPENDIX 2. Examples of hand-digitized land cover and reclassified NLCD within a $300 \mathrm{~m}$ buffer of the same four point count stops along BBS route 90038 .

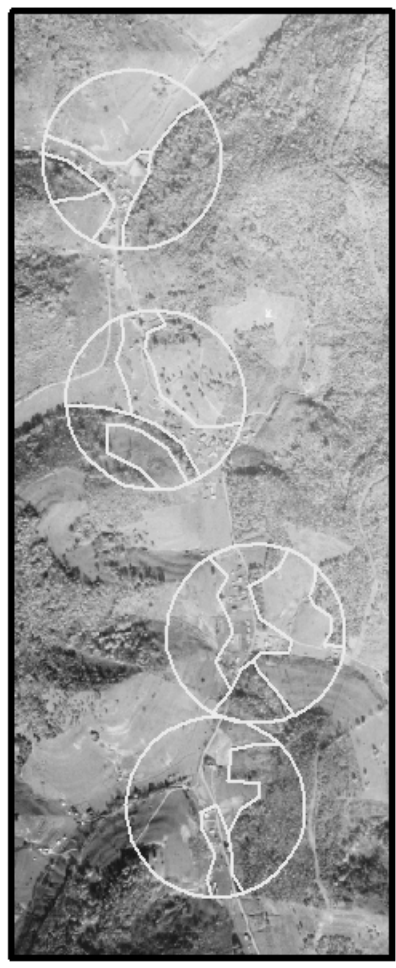

Aerial Photo - 1967

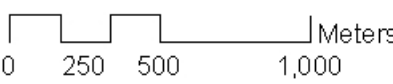

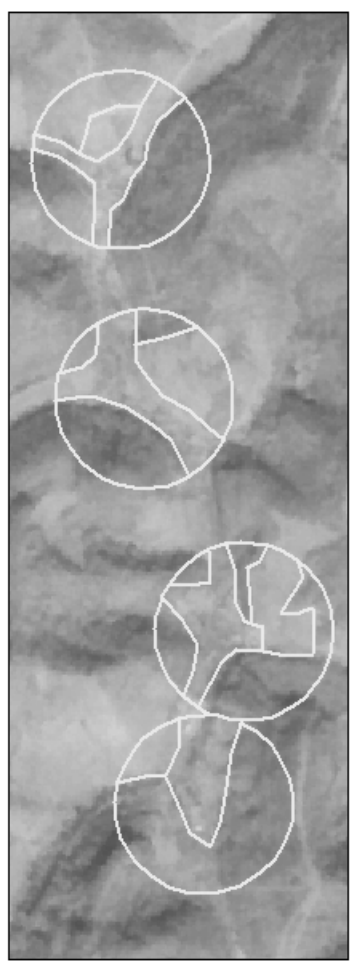

Aerial Photo - 1982
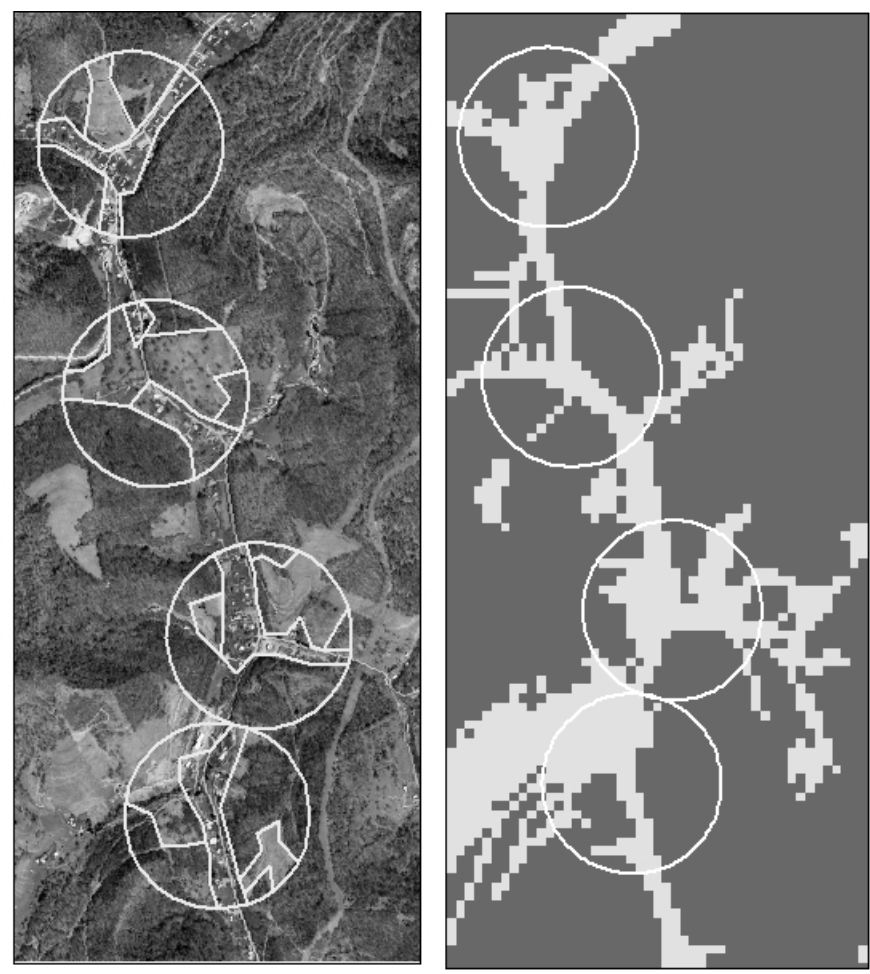

Aerial Photo - 2003

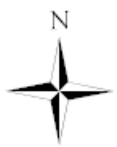

Reclassified 2001 NLCD

2001 NLCD

Value

Non-forest

Deciduous/Mixed forest 
APPENDIX 3. Step-by-step process to incorporate a general roads layer into the NLCD dataset. All steps were completed using the geographical information systems ArcMap 9.2 (ESRI, Redlands, California).

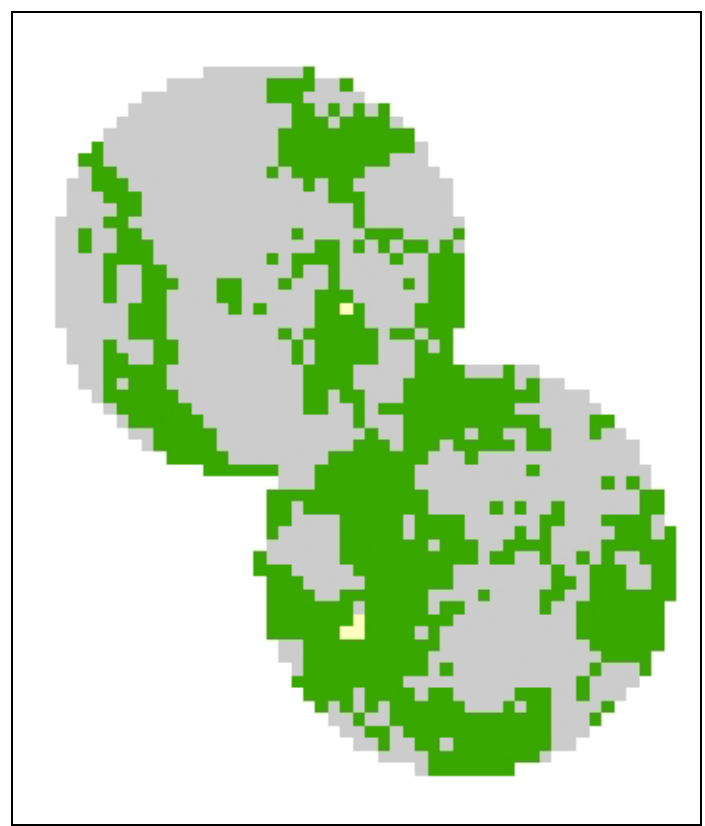

1. Clip NLCD to $500 \mathrm{~m}$ buffer around each stop with the Spatial Analyst tool 'Raster Calculator' with the cell size resampled to $10 \mathrm{~m}$. The extent in the Spatial Analyst options should be set to the $500 \mathrm{~m}$ buffer around each stop.

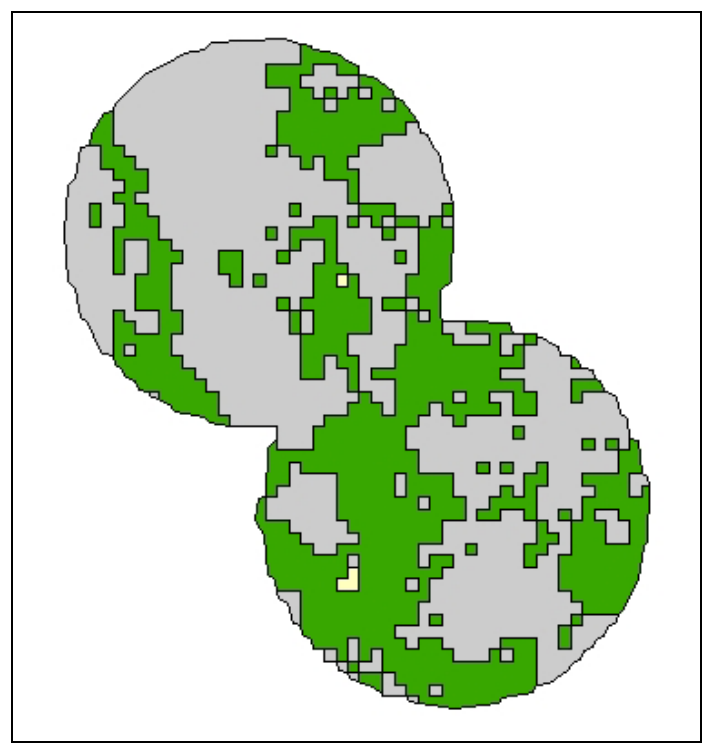

2. Convert from raster to vector with 'Raster to Polygon Feature' tool in ArcToolbox. 


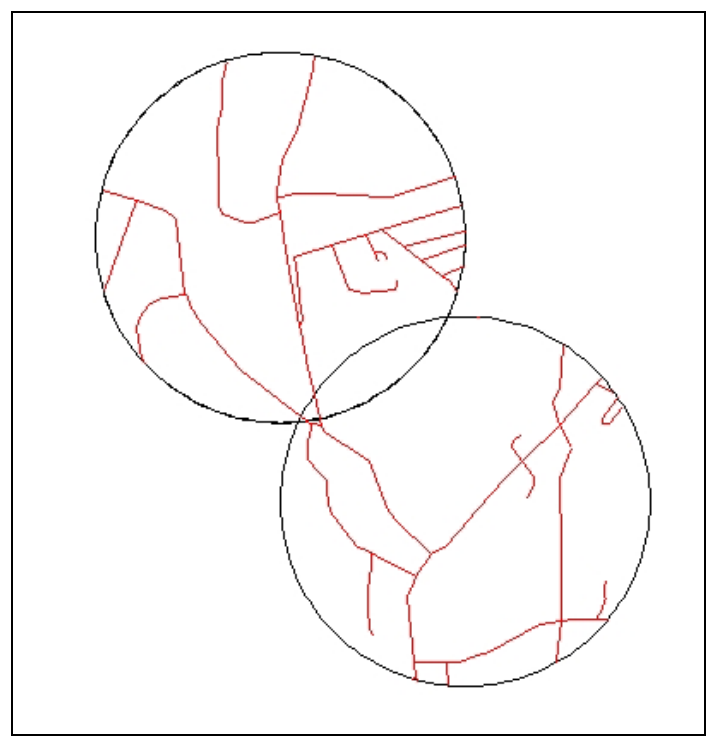

3. Use the 'Clip' tool in ArcToolbox to clip the general roads layer (red line) to same 500 $\mathrm{m}$ buffer around each stop as NLCD data.

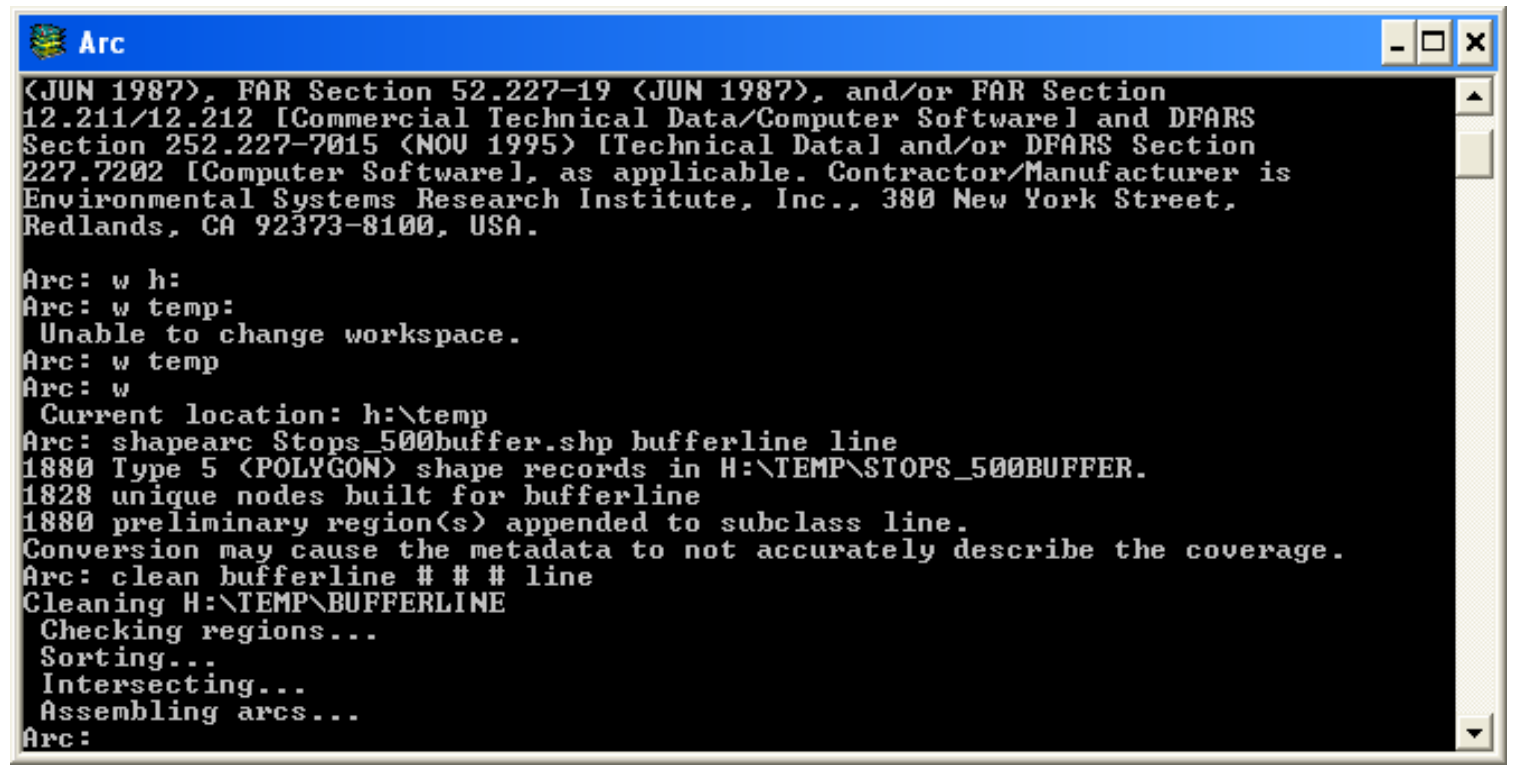

4. In ArcInfo Workstation, use the 'shapearc' and 'clean' commands in the Arc program to convert the $500 \mathrm{~m}$ buffer polygon to a line feature. 


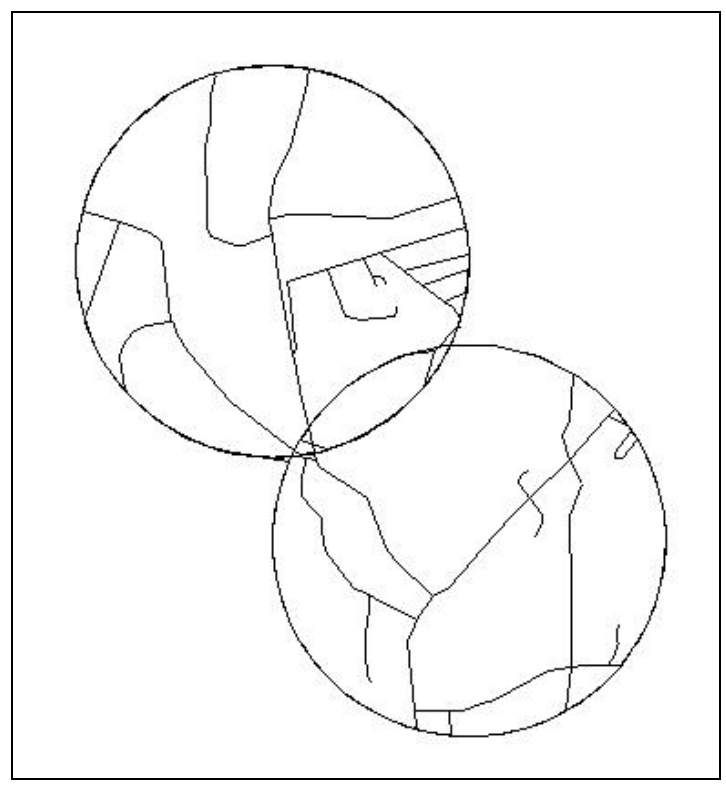

5. Use the 'Merge' tool in ArcToolbox to combine the $500 \mathrm{~m}$ clipped road and buffer line features and their attributes.

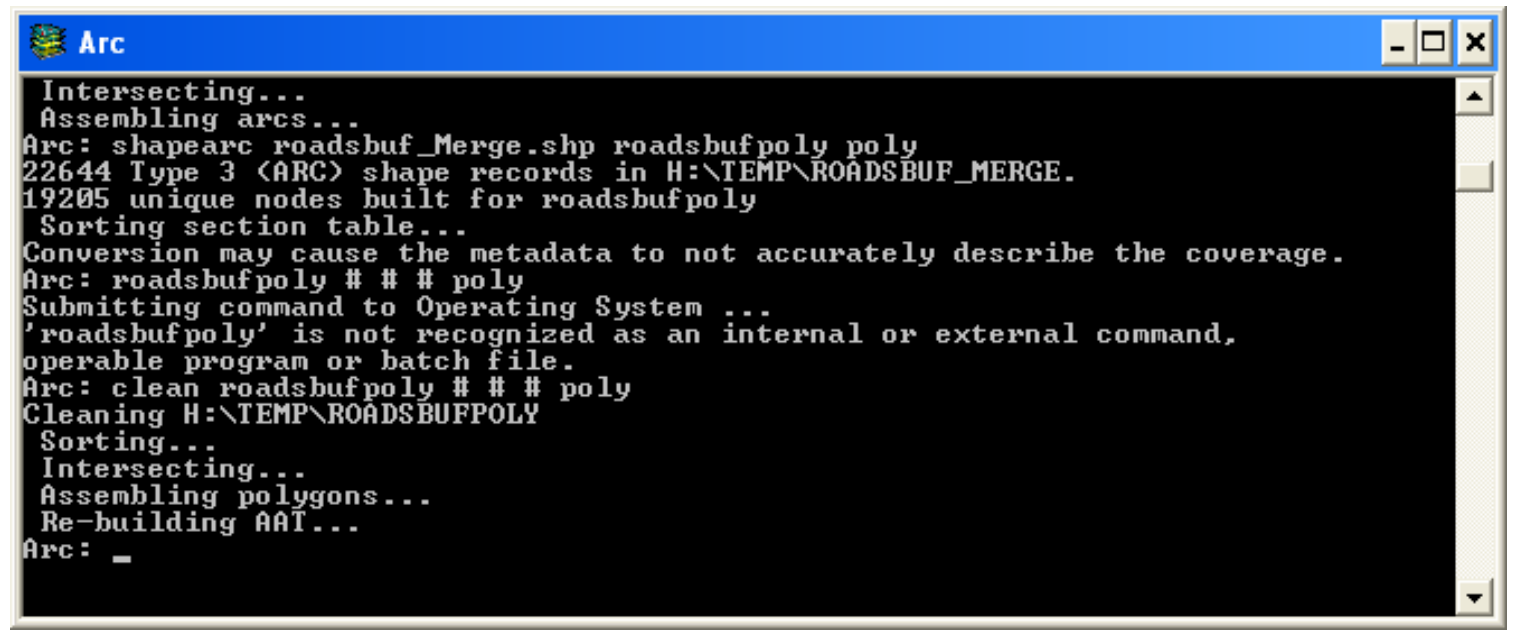

6. Use the command lines 'shapearc' and 'clean' to convert the merged road and buffer line feature to a polygon feature in Arc. 


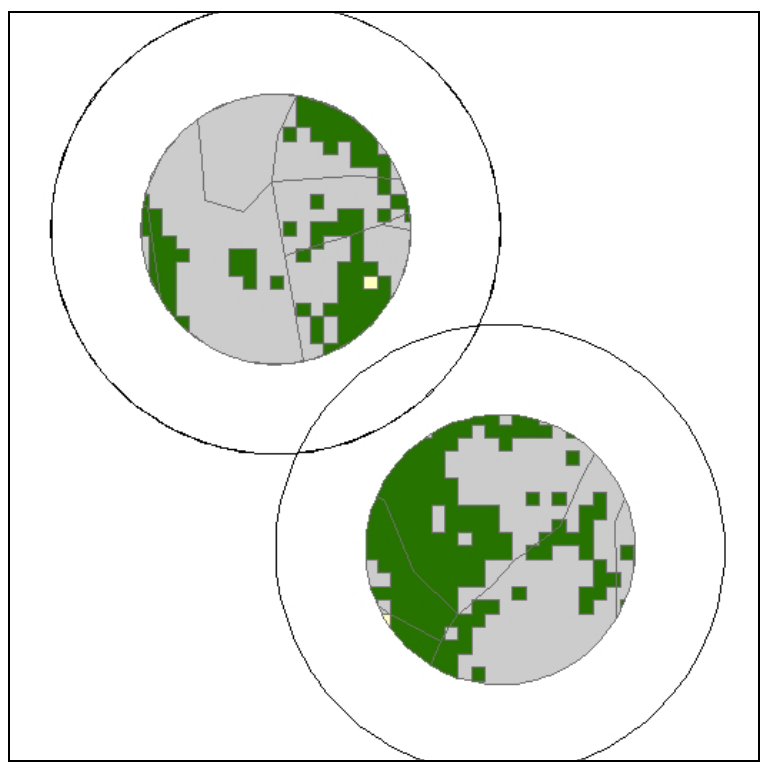

7. Using 'Union' in ArcToolbox, union the road and buffer polygon with the vector NLCD data. Union intersects all the features from the road and buffer polygon and the vector NLCD data to an output polygon. Clip the unioned polygon to $300 \mathrm{~m}(500 \mathrm{~m}$ buffer outline also shown) to create a final shapefile with a smooth land cover edge around the boundary. 
APPENDIX 4. Forest-forest and forest-nonforest edge density calculation methods. All steps were completed using the geographical information systems ArcMap 9.2 (ESRI, Redlands, California).

\section{Forest-forest edge density}

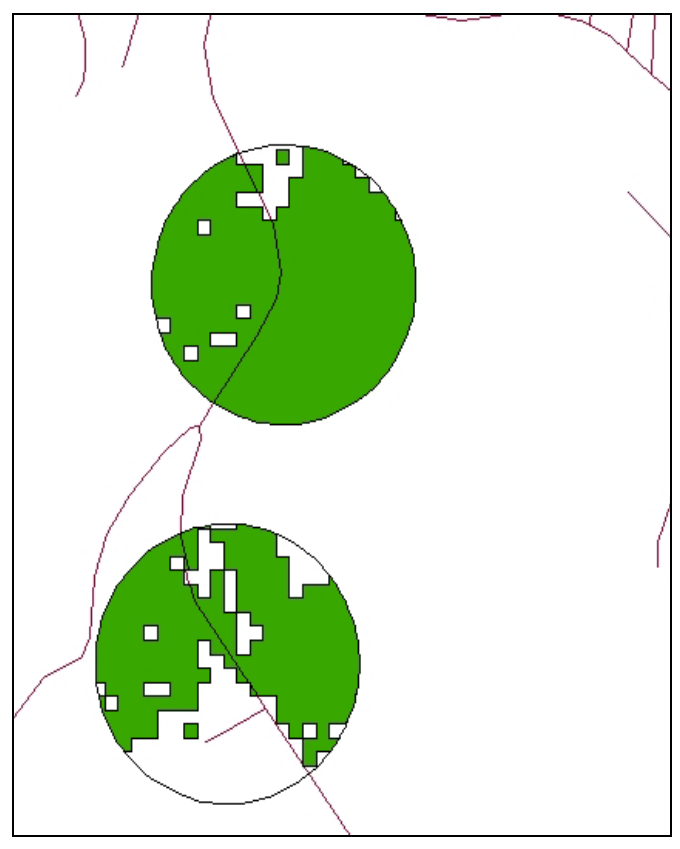

1. Create a shapefile of deciduous/mixed forest (green) within a $300 \mathrm{~m}$ buffer of each BBS stop. Use the 'Identity' tool in ArcToolbox with the general roads layer (red line) as the Input feature and the deciduous/mixed forest polygons as the 'Identity' feature. This will identify and assign all roads that fall within a deciduous/mixed forest polygon. Each deciduous/mixed forest polygon needs to be identified by which buffered stop it is associated with.

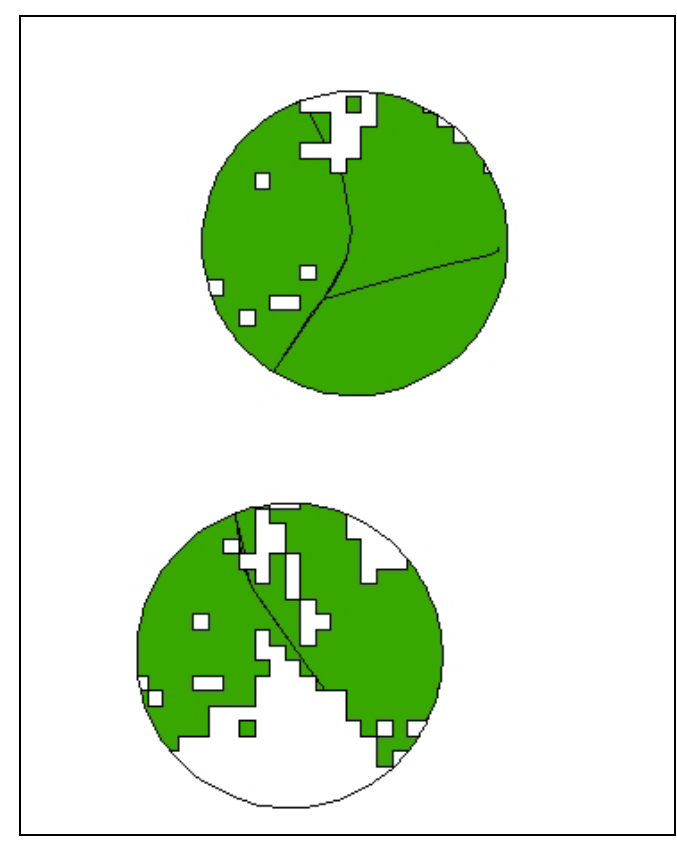

2. Select roads that have a stop I.D. Only roads within buffered stops will have an I.D. Recalculate the length of each road line. Summarize the lengths of all road lines by each buffered stop. This is the total edge caused by roads separating deciduous/mixed forest polygons within each 300-m buffered stop. 


\section{Forest-nonforest edge density}

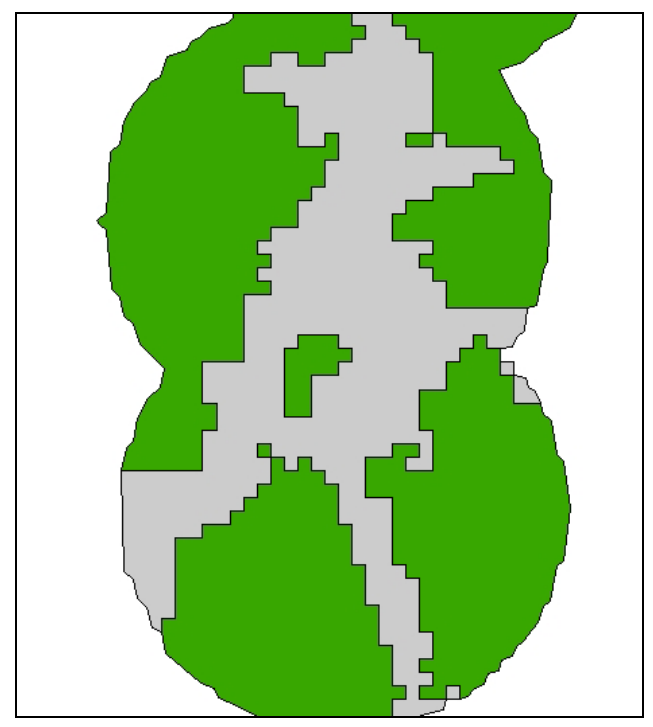

1. Start with a shapefile that includes deciduous/mixed forest (green) and non-forest (gray) within a $500 \mathrm{~m}$ buffer around each BBS stop.

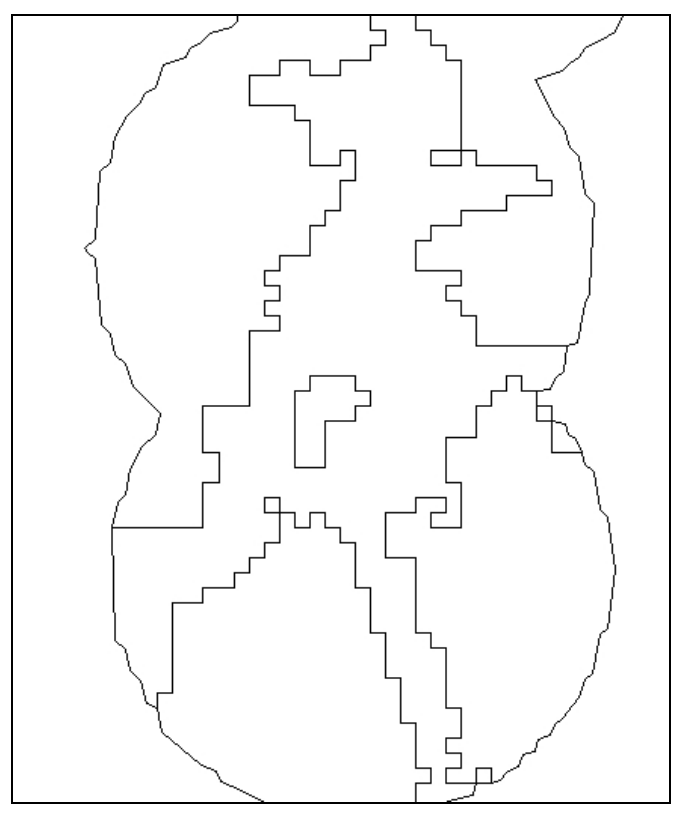

2. Convert the polygon shapefile to a line feature with the ArcToolbox tool 'Feature to Line'. 


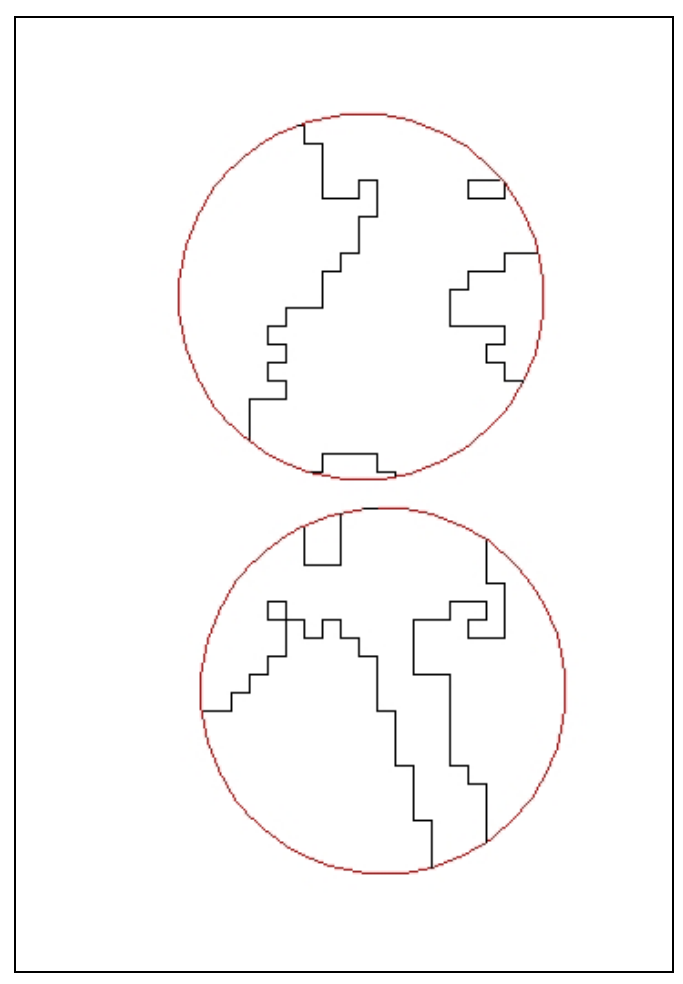

3. Use the 'Identity' tool with forest-nonforest line feature as the Input feature (black line) and the $300 \mathrm{~m}$ buffered stops as the Identity feature (red line). This will clip the 500 $\mathrm{m}$ forest-nonforest line feature to the $300 \mathrm{~m}$ buffer without including the boundary as edge and assign each forest-nonforest line feature to a buffered stop I.D. Recalculate the length of each line and summarize the length by the buffer stop I.D. This is the total edge between deciduous/mixed forest and non-forest within each 300-m buffered stop. 
APPENDIX 5. Stops with $300 \mathrm{~m}$ buffer along BBS route 90038 showing land cover change from the 1992 and 2001 National Land Cover Data (NLCD). These stops are typical of the land cover surrounding BBS stops in the Appalachian region.

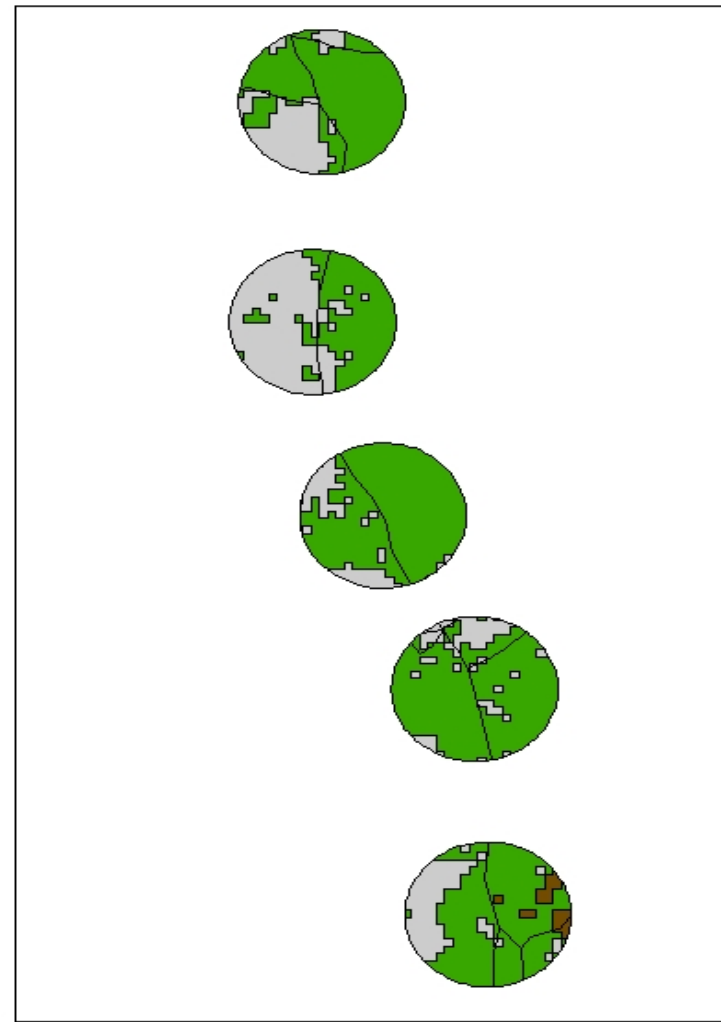

90038 - 1992 NLCD

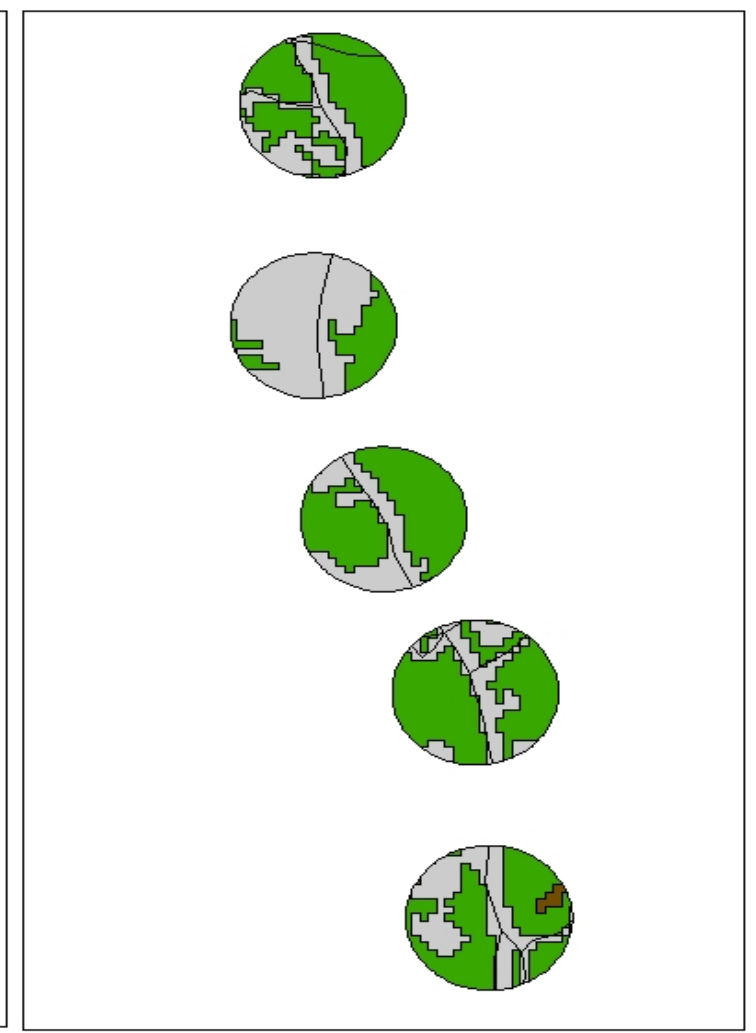

90038 - 2001 NLCD

Non-forest

Coniferous forest

Deciduous/Mixed forest

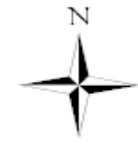


APPENDIX 6. Summary of each statistical analysis and model used in this study. DECp $=\%$ deciduous $/$ mixed forest, $\mathrm{CONp}=\%$ coniferous forest, $\mathrm{DEVp}=\%$ developed, OTHp $=\%$ other, $\mathrm{NONp}=\%$ non-forest are covariates. Metric $=$ land cover and fragmentation metrics.

\begin{tabular}{|c|c|}
\hline Analysis & Model \\
\hline $\begin{array}{l}\text { Land cover and fragmentation changes } \\
\text { based on aerial photos (early-middle } \\
\text { time period; aerial photos; } 2 \text { routes) } \\
n=68 \text { stops on } 2 \text { routes in each period }\end{array}$ & $\begin{array}{l}\text { ANOVA } \\
\text { - Class = route stop period } \\
\text { - Model metric }=\text { period route stop (route) } \\
\text { - Random effects = route stop (route) }\end{array}$ \\
\hline $\begin{array}{l}\text { CERW changes over time (early- } \\
\text { middle time period; aerial photos; } 2 \\
\text { routes) } \\
n=68 \text { stops on } 2 \text { routes in each period }\end{array}$ & $\begin{array}{l}\text { ANCOVA } \\
\text { - Class = route stop period } \\
\text { - Model CERW_AVG = period route stop (route) } \\
\text { DECp CONp DEVp OTHp } \\
\text { - Random effects = route stop (route) }\end{array}$ \\
\hline $\begin{array}{l}\text { Land cover and fragmentation changes } \\
\text { based on aerial photos (middle-late } \\
\text { time period; aerial photos; } 6 \text { routes) } \\
n=240 \text { stops on } 6 \text { routes in each } \\
\text { period } \\
n=76 \text { presence-only stops on } 6 \text { routes } \\
\text { in each period }\end{array}$ & $\begin{array}{l}\text { ANOVA } \\
\text { - Class = route stop period } \\
\text { - Model metric }=\text { period route stop (route) } \\
\text { - Random effects }=\text { route stop (route) }\end{array}$ \\
\hline $\begin{array}{l}\text { CERW changes over time (middle-late } \\
\text { time period; aerial photos; } 6 \text { routes) } \\
n=240 \text { stops on } 6 \text { routes in each } \\
\text { period }\end{array}$ & $\begin{array}{l}\text { ANCOVA } \\
\text { - Class = route stop period } \\
\text { - Model CERW_AVG = period route stop (route) } \\
\text { DECp CONp DEVp OTHp } \\
\text { - Random effects = route stop (route) }\end{array}$ \\
\hline $\begin{array}{l}\text { Land cover and fragmentation changes } \\
\text { over time (1992-2001; NLCD) } \\
n=1,377 \text { stops on } 28 \text { routes in each } \\
\text { period } \\
n=344 \text { presence-only stops on } 25 \\
\text { routes in each period }\end{array}$ & $\begin{array}{l}\text { ANOVA } \\
\text { - Class = route stop period } \\
\text { - Model metric }=\text { period route stop (route) } \\
\text { - Random effects }=\text { route stop (route) }\end{array}$ \\
\hline $\begin{array}{l}\text { CERW changes over time (1992-2001; } \\
\text { NLCD) } \\
n=1,377 \text { stops on } 28 \text { routes in each } \\
\text { period } \\
n=344 \text { presence-only stops on } 25 \\
\text { routes in each period }\end{array}$ & $\begin{array}{l}\text { ANCOVA } \\
\text { - Class = route stop period } \\
\text { - Model CERW_AVG = period route stop (route) } \\
\text { DECp CONp DEVp OTHp } \\
\text { - Random effects = route stop (route) }\end{array}$ \\
\hline $\begin{array}{l}\text { CERW's by Group } \\
(1992-2001 ; \text { NLCD) } \\
n=1,377 \text { stops on } 28 \text { routes in each } \\
\text { period }\end{array}$ & $\begin{array}{l}\text { ANOVA } \\
- \text { Class = route group } \\
\text { - Model \% difference in land cover = group route } \\
\text { (group) } \\
\text { - Random effects = group route (group) } \\
\end{array}$ \\
\hline
\end{tabular}




\section{Chapter 3}

Comparison of stop-level Breeding Bird Survey and off-road Cerulean Warbler abundance and land cover in the central Appalachians

Formatted in the style of $A u k$ 
ABSTRACT.-The North American Breeding Bird Survey (BBS) is the primary data source for population status and trends of landbirds across North America. However, questions have been raised whether the roadside surveys are representative of habitat and trends occurring in regional areas they are intended to sample. We examined if land cover, habitat characteristic, and Cerulean Warbler (Dendroica cerulea) detections were similar for 1,525 stops along 31 BBS routes and 1,375 off-road stops in the Central Appalachians using the 2001 National Land Cover Dataset. Within a 300-m buffer around each point count stop, all of the land cover and six of the eight habitat variables differed between BBS and off-road datasets. Although the off-road dataset had greater amounts of habitat characteristics Cerulean Warblers presumably prefer the BBS detected more birds per stop than the off-road dataset. BBS stops had greater densities of forestforest and forest-nonforest edge, suggesting Cerulean Warblers tolerate or select for a degree of edge in determining habitat suitability. Although three of the four land cover variables were different when the comparison was restricted to the subset of stops at which Cerulean Warblers were detected, most habitat metrics and Cerulean Warbler detections were not different between the BBS and off-road datasets. From these results, we suggest that despite habitat being different along BBS stops than off-road areas, Cerulean Warblers are able to find suitable habitat near roads. Since Cerulean Warblers were detected more frequently and at higher abundance along BBS stops, the estimated $4.1 \%$ annual decline from BBS data may be affecting a great proportion of the population than sampled by the BBS. 


\section{INTRODUCTION}

The North American Breeding Bird Survey has determined Cerulean Warbler (Dendroica cerulea) populations range-wide declined significantly at $4.1 \%$ per year during 1966-2007 (Sauer et al. 2008). This decline prompted the U.S. Fish and Wildlife Service to review the status of the Cerulean Warbler for listing as a threatened species (Federal Register 2006). Cerulean Warblers breed primarily in the Ohio and Mississippi River valleys, with the Ohio Hills and Cumberland Plateau physiographic areas comprising the core breeding range (Hamel 2000a). As a species that requires large tracts of unfragmented, mature forests with tall deciduous trees to sustain viable breeding populations (Oliarnyk 1996, Hamel 2000b), the roadside nature of the BBS may create potential biases when sampling this species.

The BBS was first established in 1966 to monitor avian populations throughout North America (O'Connor et al. 2000). Each $40 \mathrm{~km}$ BBS route consists of 50 point count stops $0.8 \mathrm{~km}$ apart along secondary roads. The routes are distributed randomly and are assumed to reflect habitats representative of that region (Donovan and Flather 2002). Routes are surveyed once each year, generally by a volunteer observer. At every stop, an observer conducts a 3 min point count in which all birds seen within a $400 \mathrm{~m}$ radius and all birds heard are recorded (U.S. Geological Survey 2007).

The BBS has become the primary data source on the status and population changes of breeding birds in North America (Sauer et al. 1994) and is used by the U.S. Fish and Wildlife Service, Canadian Wildlife Service, state wildlife agencies, and Partners in Flight to establish avian conservation priorities (U.S. Geological Survey 2007). Despite its widespread use, potential biases exist because regional population trends are based on surveys conducted along roads. The roadside surveys may not adequately sample certain habitat types, and changes in both habitat and birds may be different along roads than off-road (U.S. Geological Survey 2007). In addition, bird abundances along roads may differ from those in off-road habitats. Only two studies have examined land cover along BBS routes (Bart et al. 1995, Keller and Scallan 1999), and two have compared land cover and bird abundances between the BBS and off-road areas (Betts et al. 2007, Harris and Haskell 2007) in eastern North America. These 
studies conducted analyses at the route-level, examining land cover or bird abundance along the BBS route path, or for the composite of stops that comprise the BBS routes, rather than at individual stops. Lost in this approach are stop-specific characteristics, such as slope position, aspect, and microhabitat features, that can influence the occurrence and abundance of Cerulean Warblers or other species.

The persistent decline of Cerulean Warblers in the core breeding range by the BBS and the potential biases of using BBS data led us to examine if the declines reflect changes at sampled BBS routes, or reflect Cerulean Warbler population changes occurring in the regional landscape. If population trends are biased because roadside habitat and bird trends are not representative of off-road habitat and bird trends, this will affect the conservation efforts of federal, state, and non-governmental organizations. Furthermore, several reviews of the BBS have given high priority to determining the potential bias associated with the roadside nature of the BBS (O'Connor et al. 2000, U.S. Geological Survey 2007). As such, the objective of this study was to compare habitat and Cerulean Warbler detections at the stops on the BBS roadside surveys and at points in an off-road dataset in the Central Appalachians to determine if off-road habitat and bird abundances are being accurately assessed by roadside surveys.

\section{METHODS}

Study Area. - The study area lies within the West Virginia, Kentucky, and Ohio portions of Bird Conservation Region (BCR) 28-Appalachian Mountains (Fig. 1). BCR 28 is generally classified as dominated by oak (Quercus spp.)-hickory (Carya spp.) and associated deciduous forest types. The study area falls within the National Land Cover Dataset (NLCD) mapping zones of 47, 53, 61, and 62 (Homer et al. 2004).

The Ohio Hills, Northern Cumberland Plateau, and Mid Atlantic Ridge and Valley physiographic areas (www.partnersinflight.org/bcps/pifplans.htm) of BCR 28 comprise the majority of the study area and are considered the core breeding range of the Cerulean Warbler (Hamel 2000a). The Ohio Hills ( $\sim 8$ million ha) is defined by dissected plateaus ranging from $150-450 \mathrm{~m}$ in elevation (Rosenberg 2000). Oak-hickory forests cover roughly $54 \%$ of this region. Agriculture and urban/developed areas are the other 
dominant land cover types, covering $40 \%$ of the region. The Northern Cumberland Plateau ( $\sim 5.5$ million ha) is a rolling hills tableland ranging from $300-580 \mathrm{~m}$ in elevation (Demarest 2003). The most common land cover type is mixed mesophytic forests dominated by oaks and hickories. This is one of the most heavily forested eastern physiographic regions; however, the species composition and vegetative structure differ from historical conditions within these forests. Widespread timber harvesting and fire suppression have limited old-growth and early-successional habitat. The Mid Atlantic Ridge and Valley region ( $\sim 5$ million ha) is dominated by long mountainous ridges and intervening valleys (Rosenberg 1999). Similar to the other physiographic areas, the vegetation primarily consists of oak and oak-hickory forests. While human populations remain relatively sparse, natural resource extraction is an important land use of the area (Pashley et al. 2000).

Avian Data. - We used bird count data collected on BBS routes and off-road routes in the study area. The off-road routes were surveyed by numerous individuals for various programs in support of avian population monitoring objectives of the West Virginia Division of Natural Resources and the Kentucky Department of Fish and Wildlife Resources. Off-road point count stops were placed at least $250 \mathrm{~m}$ apart, but the number of stops within each route varied. Point count length in the off-road dataset ranged from 3 to $10 \mathrm{~min}$, with data recorded within intervals of 3, 5, and $10 \mathrm{~min}$. For comparison with BBS results, we used data from the first 3-min interval. We were unable to include off-road point count data from the Ohio portion of BCR 28 because existing data only had a 5-min interval. The maximum Cerulean Warbler abundance was used for stops that were surveyed more than once in a breeding season; this occurred for around $50 \%$ of stops. We confirmed the off-road status of the routes by identifying surrounding land cover with the 2001 National Land Cover Dataset (NLCD). We measured the spatial autocorrelation with the ArcMap tool Moran's I (ESRI, Redlands, California), and determined that the off-road routes are randomly distributed throughout the study area, and therefore assumed to reflect the regional off-road habitat (Fig. 1).

Both types of routes had to meet several criteria to be included in the study. Routes were included if coordinates for stops had been collected by the route observers and were surveyed at least three years within a five-year time bracket around the 2001 
NLCD. We only included routes with stop-level coordinates collected by observers so they would be as accurately placed as possible; although stops are set at $0.8 \mathrm{~km}$ intervals, observers sometimes adjust stop locations to safer or quieter stopping points (D. Dawson, pers. comm.), so stop locations mapped by BBS staff are not always accurate. The three to five year period provides a more accurate measure of the response from migratory birds to habitat changes than one year, which would be more of a snapshot in time, or a longer period (e.g. 8-10 years) that may be a composite of avian responses to habitat changes not reflected in the land cover data. A total of 1,525 stops along 31 BBS routes of the available 88 routes located in the study area and 1,375 off-road stops in the study area had stop coordinates and were run consistently enough to be included in the analysis (Fig. 1).

Count data for Cerulean Warblers at stops along the selected BBS routes were obtained from BBS staff at the USGS Patuxent Wildlife Research Center, or were downloaded from the BBS website (http://www.pwrc.usgs.gov/bbsapps/index.cfm). We obtained the off-road point count data from the West Virginia Division of Natural Resources and the Kentucky Department of Fish and Wildlife Resources.

Land Cover and Habitat Metrics. - We measured land cover characteristics of the stops from the 2001 NLCD. The NLCD provides a consistent, 30-m resolution dataset for the conterminous United States that classifies land cover using Anderson I and II land cover classes (Anderson 1976). We reclassified the data into four land cover types: deciduous/mixed forest, coniferous forest, developed, and composite. We distinguished between deciduous/mixed and coniferous forests because Cerulean Warblers are not known to use coniferous forests (Hamel 2000b). The composite land cover collapsed all 2001 NLCD types not included by the three other land cover types. Thogmartin et al. (2004) found inconsistencies in NLCD mapping and recommended separating out land cover types important to the species of interest and combining other types. We chose to keep the developed type separate to examine if more developed areas were located near roads compared to off-road.

Land cover was summarized within a 300-m buffer around each stop, using the geographic information system software ArcMap, version 9.2 (ESRI, Redlands, California). Although Cerulean Warblers are rarely detected beyond $100 \mathrm{~m}$ (Bosworth 
2003), the 300 -m buffer (28.3 ha total area) is large enough to incorporate territories of Cerulean Warblers detected within $100 \mathrm{~m}$ of a stop; reported mean Cerulean Warbler territory size range from 0.21 ha (Roth 2004) to 1.04 ha (Oliarnyk and Robertson 1996). We used the ArcMap 'Buffer' tool to define the area within $300 \mathrm{~m}$ of each stop and then calculated the area of each land cover within the buffered stop. We used the percentage of each land cover type for analyses because raster grid cells do not create a perfect circle around each of the route stops and as a result, the total area around each buffered stop varies slightly around 28.3 ha.

Because Cerulean Warblers prefer large tracts of unfragmented deciduous forests (Hamel 2000b, Weakland and Wood 2005), we calculated several forest fragmentation metrics for each BBS and off-road stop: maximum size forest patch, core forest area, forest-forest edge density, forest-nonforest edge density, and distance to forested stream. A general roads layer from the U.S. Detailed Streets, part of StreetMap USA (http://www.esri.com/metatdata/esriprof80.dtd) was incorporated into the 2001 NLCD because the 30-m cell size of the NLCD may be too large to take into account small roads and trails that would affect the calculation of the fragmentation metrics (see Appendix 3 of Ch. 2 for detailed road methods). Additionally, to provide a better representation of the land cover surrounding small roads and trails, the NLCD was resampled to a 10-m cell size. The metrics maximum size forest patch, core forest area, and forest-forest edge density were calculated for the deciduous/mixed forest type, because coniferous forest is not considered suitable Cerulean Warbler habitat (Hamel 2000b). Maximum size forest patch (ha) is the largest contiguous deciduous/mixed forest patch within a buffer. Mean core forest area was calculated with a $60 \mathrm{~m}$ buffer because edge effects are known to occur within $50 \mathrm{~m}$ of a forest edge (Paton 1994). Mean core forest was divided by total area to obtain a percentage of core forest area in each buffer. Forest-forest edge density $(\mathrm{m} / \mathrm{ha})$ is the amount of linear edge created by a road splitting deciduous/mixed forest patches relative to the total land area of each buffered stop. Forest-nonforest edge density is the amount of linear edge separating deciduous/mixed forest and non-forest land cover relative to the total land area of each buffered stop (see Appendix 4 of Ch. 2 for detailed edge density methods). Finally, streams from the National Hydrography Dataset (http://nhd.usgs.gov/index.html) were overlaid on deciduous and mixed forest 
land cover cells to calculate the shortest straight line distance from each stop to a forested stream.

We also calculated variables describing physiographic characteristics that may be important for Cerulean Warblers, including elevation, aspect, and relative slope position, from the National Elevation Dataset (http://ned.usgs.gov/) at a 30-m cell size. These variables were recorded at each BBS and off-road stop, not averaged within the 300-m buffer. Aspect was transformed into values ranging from zero to two, with zero indicating southwest facing slopes and two indicating the more productive growing areas of northeast facing slopes (Beers et al. 1966). Finally, relative slope position was measured using surface hydrological analysis to identify the accumulated weight of all cells flowing into downslope cells based on the flow direction (Wilds 1996). Relative slope position is the percent distance of a particular point from the nearest slope bottom $(0 \%)$ to the nearest ridge (100\%; Wilds 1996$)$.

Statistical Analyses. - All statistical analyses were conducted using SAS (SAS Institute Inc. 2004) with $\alpha=0.10$. Univariate analyses determined that no variables, except the previously transformed aspect (Beers transformation), were normally distributed. Variable were transformed using the most appropriate method to achieve normality. We used an arcsine square root transformation on each land cover, forest core area, and relative slope position because they all are percentages. The maximum size forest patch, forest-forest edge density, forest-nonforest edge density, elevation, and distance to nearest forested stream had logarithmic transformations. The average and maximum Cerulean Warbler detections were transformed using a square root transformation due to their poisson distribution (Zar 1996).

We compared the four land cover classes and eight fragmentation or physiographic variables between the BBS and off-road datasets using ANOVA (Ritchie et al. 1998). The ANOVA model included route, status (BBS or off-road stop), and route within status. We repeated the ANOVA using only stops where Cerulean Warblers were detected at least one year during 1999-2003. We compared Cerulean Warbler detections between BBS and off-road datasets for all stops and presence-only stops using ANCOVA (Welsh, Jr. and Ollivier 1998) with the variables route, status, and route within status. Covariates were untransformed percentage of each land cover. Route within status was 
the error term in all ANOVA and ANCOVA models to test for differences between the BBS and off-road stops. The all stop analysis allows the examination of habitat and bird abundance across a broad landscape where Cerulean Warblers are known to occur; in the presence-only analysis we are able to examine BBS and off-road habitat at a local scale where Ceruleans actually were detected.

\section{RESULTS}

All stops. - Based on the 2001 NLCD, the off-road stops had greater amounts of deciduous/mixed and coniferous forests, whereas the roadside BBS stops had greater amounts of developed and composite land covers (Table 1). BBS stops had larger deciduous/mixed forest patches, as well as greater densities of forest-forest and forestnonforest edge. The off-road stops were farther away from forested streams, at higher elevations, and had a higher relative slope position than the BBS stops. The amount of core forest, and aspect did not differ between the BBS and off-road datasets.

More Cerulean Warblers were detected per stop on BBS stops than on off-road stops (Table 1). Cerulean Warblers were detected on 17\% of BBS stops and $12 \%$ of offroad stops. Similarly, the mean maximum Cerulean Warbler count was greater along BBS stops.

Presence-only stops. — The 253 BBS stops along 25 routes and 169 off-road stops that had Cerulean detections during 1999-2003 were included in the presence-only analysis. Off-road stops had greater amounts of deciduous/mixed and coniferous forests than BBS stops (Table 2). There was more developed land cover around BBS stops, but no difference in the composite land cover between the BBS and off-road datasets. Offroad stops occurred in larger sized forest patches. BBS stops had greater densities of forest-forest and forest-nonforest edge. There were no differences between the BBS and off-road datasets for any of the remaining variables, including Cerulean Warbler average and mean maximum detections per stop. 


\section{DiscussiON}

Most land cover variables were found in different amounts in areas near roads compared to those off-road. As the dominant land cover of the study area, deciduous/mixed forest occurred in greater amounts at off-road stops for all stops and for the set of stops at which Cerulean Warblers were detected (Tables 1 and 2). Greater amounts of developed and composite land cover, mainly agricultural land, occurred at all BBS stops and for the set with Ceruleans present. Our results are similar to a study that compared roadside point counts with off-road point counts ( $>200 \mathrm{~m}$ from road) that also found roadside areas had less forested land cover and more developed and agricultural land cover than off-road areas (Keller and Scallan 1999). Our study provides further support that roadside areas are more likely to have development and that broad land cover categories along BBS routes are fundamentally different than the surrounding regional land cover.

Along with more deciduous/mixed forest, other variables that may indicate suitable Cerulean Warbler habitat, such as maximum size forest patch and core forest area (Hamel 2000b, Oliarnyk 1996), had higher values at off-road stops in the presenceonly stops dataset. The greater density of forest-nonforest edge at BBS stops for the all stops and presence-only stops analyses illustrates that areas near roads are more fragmented than those away from roads (Appendix 1). All four land cover variables and six of the eight fragmentation or physiographic variables differed significantly between BBS and off-road stops. Other studies have documented that land cover changed over several time periods at the same rate between BBS routes and the surrounding landscape (Bart et al. 1995, Keller and Scallan 1999). However, within each time period, these studies determined that the same land cover type was found in different amounts between BBS routes and the surrounding landscape (Bart et al. 1995, Keller and Scallan 1999). These studies support our results that land cover at BBS stops is different from surrounding land cover, suggesting habitat surrounding BBS stops is not representative of the regional habitat; therefore BBS bird population trend estimates may not reflect true regional population trends of the species they intend to survey. However, maximum size forest patch, forest-forest and forest-nonforest edge densities were the only habitat variables to differ in the presence-only analysis. This suggests that in the specific case of 
the Cerulean Warbler, the microhabitat features they select for can be found both near and away from roads.

Although many habitat features Cerulean Warblers seem to prefer in the Appalachian region (deciduous/mixed forest, maximum size forest patch, and higher elevations; Oliarnyk 1996, Hamel 2000b, Weakland and Wood 2005) were found in higher amounts at off-road stops, BBS stops had nearly twice as many Cerulean Warbler detections per stop as the off-road stops (Table 1). Cerulean Warblers were detected on $17 \%$ of BBS stops and $12 \%$ of off-road stops. However, there was no difference in Cerulean Warbler detections at presence-only stops (Table 2). Keller and Fuller (1995) found no difference in Cerulean Warbler detections between roadside points and points 200 or $400 \mathrm{~m}$ off-road within a large block of forest where roads created the few forest openings. Cerulean Warblers may be selecting for habitat near roads because it provides a break in an otherwise continuous canopy at BBS stops. Also, the canopy break created by a road could be concentrating Cerulean Warblers near roads, whereas they may be more dispersed in off-road areas where canopy breaks such as canopy gaps are also more dispersed. Most of the fragmentation and physiographic variables were not different in the presence-only dataset, suggesting that the habitat features Cerulean Warblers select for can be found both near and away from roads. Other studies that compared point counts along roads with off-road points in the same habitat found no difference in avian composition or abundance (Hanowski and Niemi 1995, Hutto et al. 1995). Further, the lack of a difference in most of the fragmentation and physiographic variables suggests that these variables may play a more important role in Cerulean Warbler habitat selection than simply large, contiguous deciduous and mixed forests.

Other studies have found Cerulean Warblers use predominantly northeastern aspects, although they are detected on all aspects (Weakland and Wood 2005, Wood et al. 2005). However, we detected Cerulean Warblers primarily at stops with a southerly aspect for both the BBS and off-road stops.

The fragmentation metrics forest-forest edge density and forest-nonforest edge density may be playing a key role in determining habitat suitability for Cerulean Warblers as both edge metrics were found in greater amounts along BBS stops. Some degree of edge habitat along BBS stops may be creating structural diversity within the 
habitat, similar to that created by small, isolated canopy gaps and mid-sized gaps created by small roads and trails, that Cerulean Warblers seem to prefer (Weakland and Wood 2005, Perkins 2006). Although fragmentation is believed to be a key factor in the decline of Cerulean Warblers (Hamel et al. 2004), Trzcinski et al. (1999) documented that fragmentation does not consistently have a negative effect on all forest bird species. There may be a degree of fragmentation and edge habitat that Cerulean Warblers tolerate or select for in determining habitat suitability. While a certain amount of edge habitat is inevitable with the roadside BBS surveys, Cerulean Warblers were detected more frequently along BBS stops in the all-stop analysis and there was no difference in the presence-only analysis. This supports that Cerulean Warblers tolerate a degree of edge habitat and suitable habitat can be found near roads. As interest in Cerulean Warbler conservation and management continues (Hamel 2000a, Hamel et al. 2004), research should explore the degree at which edge and canopy gap habitat changes from being suitable to unsuitable for Cerulean Warblers.

Along BBS roadside surveys, Cerulean Warblers have been declining 4.1\% per year range-wide from 1966-2007 (Sauer et al. 2008). Because Cerulean Warblers were detected more frequently and at higher abundance along BBS stops than off-road stops, our results suggest the potential that the BBS determined decline may be affecting a larger proportion of the Cerulean Warbler population.

\section{LITERATURE CITED}

Anderson, J. F., E. E. Hardy, J. T. Roach, and R. E. Witmer. 1976. A land use and land cover classification system for use with remote sensor data, U.S. Geological Survey Professional Paper 964. U.S. Geological Survey, Washington, D.C.

Bart, J., M. Hofschein, and B. G. Peterjohn. 1995. Reliability of the Breeding Bird Survey: effects of restricting surveys to roads. The Auk 112:758-761.

Beers, T. W., P. E. Dress, and L. C. Wensel. 1966. Aspect transformation in site productivity research. Journal of Forestry 64:691-692.

Betts, M. G., D. Mitchell, A. W. Diamond, and J. Bety. 2007. Uneven rates of landscape change as a source of bias in roadside wildlife surveys. Journal of Wildlife Management 71:2266-2273. 
Bosworth, S. B. 2003. Cerulean Warbler Relative Abundance and Frequency of Occurrence Relative to Large-Scale Edge. M.S. thesis, West Virginia University, Morgantown.

Demarest, D. 2003. Northern Cumberland Plateau, Physiographic Area 21-Executive Summary. Partners in Flight. [Online.] Available at www.partnersinflight.org/bcps/pl_21sum.htm.

Donovan, T. M., and C. H. Flather. 2002. Relationships among North American songbird trends, habitat fragmentation, and landscape occupancy. Ecological Applications 12:364-374.

Federal Register. 2006. Endangered and Threatened Wildlife and Plants; 12-month finding on a petition to list the Cerulean Warbler (Dendroica cerulea) as threatened with critical habitat. 71:70717-70733.

Hamel, P. B. 2000a. Cerulean Warbler status assessment. U.S. Fish and Wildlife Service. [Online.] Available at www.fws.gov/midwest/eco_serv/soc/birds/cerw/cerw-sa.pdf.

Hamel, P. B. 2000b. Cerulean Warbler (Dendroica cerulea). In The Birds of North America, no. 511 (A. Poole and F. Gill, Eds.). Academy of Natural Sciences, Philadelphia, and American Ornithologists' Union, Washington, D.C.

Hamel, P. B., D. K. Dawson, and P. D. Keyser. 2004. How we can learn more about the Cerulean Warbler (Dendroica cerulea). Auk 121:7-14.

Hanowski, J. M., and G. J. Niemi. 1995. A comparison of on- and off-road bird counts: Do you need to go off road to count birds accurately? Journal of Field Ornithology 66:469-483.

Harris, J. B. C., and D. G. Haskell. 2007. Land cover sampling biases associated with roadside bird surveys. Avian Conservation and Ecology. 2:12.

Homer, C., C. Huang, L. Yang, B. Wylie, and M. Coan. 2004. Development of a 2001 National Land-Cover Database for the United States. Photogrammetric Engineering and Remote Sensing 70:829-840.

Hutto, R. L., S. L. Hej1, J. F. Kelly, and S. M. Pletschet. 1995. A comparison of bird detection rates from on-road versus off-road point counts in northern Montana. Pages 103-110 in Monitoring Bird Populations by Point Counts (C. J. Ralph, J. R. Sauer, and S. Droege, Eds.). USDA Forest Service General Technical Report PSW-GTR149. Albany, California.

Keller, C. M. E., and M. R. Fuller. 1995. Comparison of birds detected from roadside and off-road point counts in the Shenandoah National Park. Pages 111-115 in Monitoring Bird Populations by Point Counts (C. J. Ralph, J. R. Sauer, and S. Droege, Eds.). General Technical Report PSW-GTR-149, USDA Forest Service, Albany, California. 
Keller, C. M. E., and J. T. Scallan. 1999. Potential roadside biases due to habitat changes along Breeding Bird Survey routes. Condor 101:50-57.

O’Connor, R. J., E. Dunn, D. H. Johnson, S. L. Jones, D. Petit, K. Pollock, C. R. Smith, J. L. Trapp, and E. Welling. 2000. A programmatic review of the North American Breeding Bird Survey. Report of a peer review panel. Patuxent Wildlife Research Center, Laurel, Maryland.

Oliarnyk, C. J. 1996. Habitat Selection and Reproductive Success in a Population of Cerulean Warblers in Southeastern Ontario. M.S. thesis. Queen's University, Kingston, Ontario.

Oliarnyk, C. J., and R. J. Robertson. 1996. Breeding behavior and reproductive success of Cerulean Warblers in southeastern Ontario. Wilson Bulletin 108:673-684.

Pashley, D. N., C. J. Beardmore, J. A. Fitzgerald, R. P. Ford, W. C. Hunter, M. S. Morrison, K. V. Rosenberg. 2000. Partners In Flight: Conservation of the land birds of the United States. American Bird Conservancy, The Plains, Virginia.

Paton, P. W. C. 1994. The effect of edge on avian nest success: how strong is the evidence? Conservation Biology 8:17-26.

Perkins, K. A. 2006. Cerulean Warbler Selection of Forest Canopy Gaps. M.S. thesis. West Virginia University, Morgantown.

Ritchie, M. E., D. Tilman, and J. M. H. Knops. 1998. Herbivore effects on plants and nitrogen dynamics in oak savanna. Ecology 79:165-177.

Rosenberg, K. 1999. Mid-Atlantic Ridge and Valley, Physiographic Area 12-Executive Summary. Partners in Flight. [Online.] Available at www.partnersinflight.org/bcps/pl_12sum.htm.

Rosenberg, K. 2000. Ohio Hills, Physiographic Area 22-Executive Summary. Partner in Flight. [Online.] Available at www.partnersinflight.org/bcps/pl_22sum.htm.

Roth, K. L. 2004 Cerulean Warbler breeding biology in Big Oaks National Wildlife Refuge, Madison, IN. M.S. thesis. Ball State University, Muncie.

SAS Institute Inc. 2004. SAS software. version 9.1. SAS Institute Inc., Cary, North Carolina.

Sauer, J. R. 1999. Combining information from monitoring programs: complications associated with indices and geographic scale. In Strategies for bird conservation: The Partners in Flight planning process (R. Bonney, D. N. Pashley, R. J. Cooper, and L. Niles, Eds.). Cornell Lab of Ornithology, Ithaca, New York.

Sauer, J. R., J. E. Hines, and J. Fallon. 2008. The North American Breeding Bird Survey, Results and Analyses 1966-2007. version 5.15.2008. U.S. Geological Survey 
Patuxent Wildlife Research Center, Laurel, Maryland. [Online.] Available at www.mbr-pwrc.usgs.gov/bbs/bbs.html.

Sauer, J.R., B.G. Peterjohn, and W.A. Link. 1994. Observer differences in the North American Breeding Bird Survey. Auk 111:50-62.

Trzcinski, M. K., L. Fahrig, and G. Merriam. 1999. Independent effects of forest cover and fragmentation on the distribution of forest breeding birds. Ecological Applications 9:586-593.

U.S. Geological Survey. 2007. Strategic plan for the North American Breeding Bird Survey: 2006-2010: U.S. Geological Survey Circular 1307, 19 p.

Weakland, C. A., and P. B. Wood. 2005. Cerulean Warbler (Dendroica cerulea) microhabitat and landscape-level habitat characteristics in southern West Virginia. Auk 122:497-508.

Welsh, Jr., H. H., and L. M. Ollivier. 1998. Stream amphibians as indicators of ecosystem stress: a case study from California's redwoods. Ecological Applications 8:11181132.

Wilds, S. 1996. Gradient Analysis of the Distribution of Flowering Dogwood (Cornus florida L.) and Dogwood Anthracnose (Discula destructive Redlin.) in Western Great Smoky Mountains National Park. M.S. thesis. University of North Carolina, Chapel Hill.

Wood, P. B., J. P. Duguay, and J. V. Nichols. 2005. Cerulean Warbler use of regenerated clearcut and two-age harvests. Wildlife Society Bulletin 33:851-858.

Zar, J. H. 1996. Biostatistical Analysis, $3^{\text {rd }}$ Edition. Prentice Hall, Upper Saddle River, New Jersey. 
TABLE 1. Comparison of land cover and habitat metrics using 2001 NLCD data, and Cerulean Warbler detections during 1999-2003 between the BBS ( $n=1,525$ stops on 31 routes) and off-road ( $n=1,375$ stops) datasets. (FF edge density $=$ Forest-forest edge density, FNF edge density = Forest-nonforest edge density).

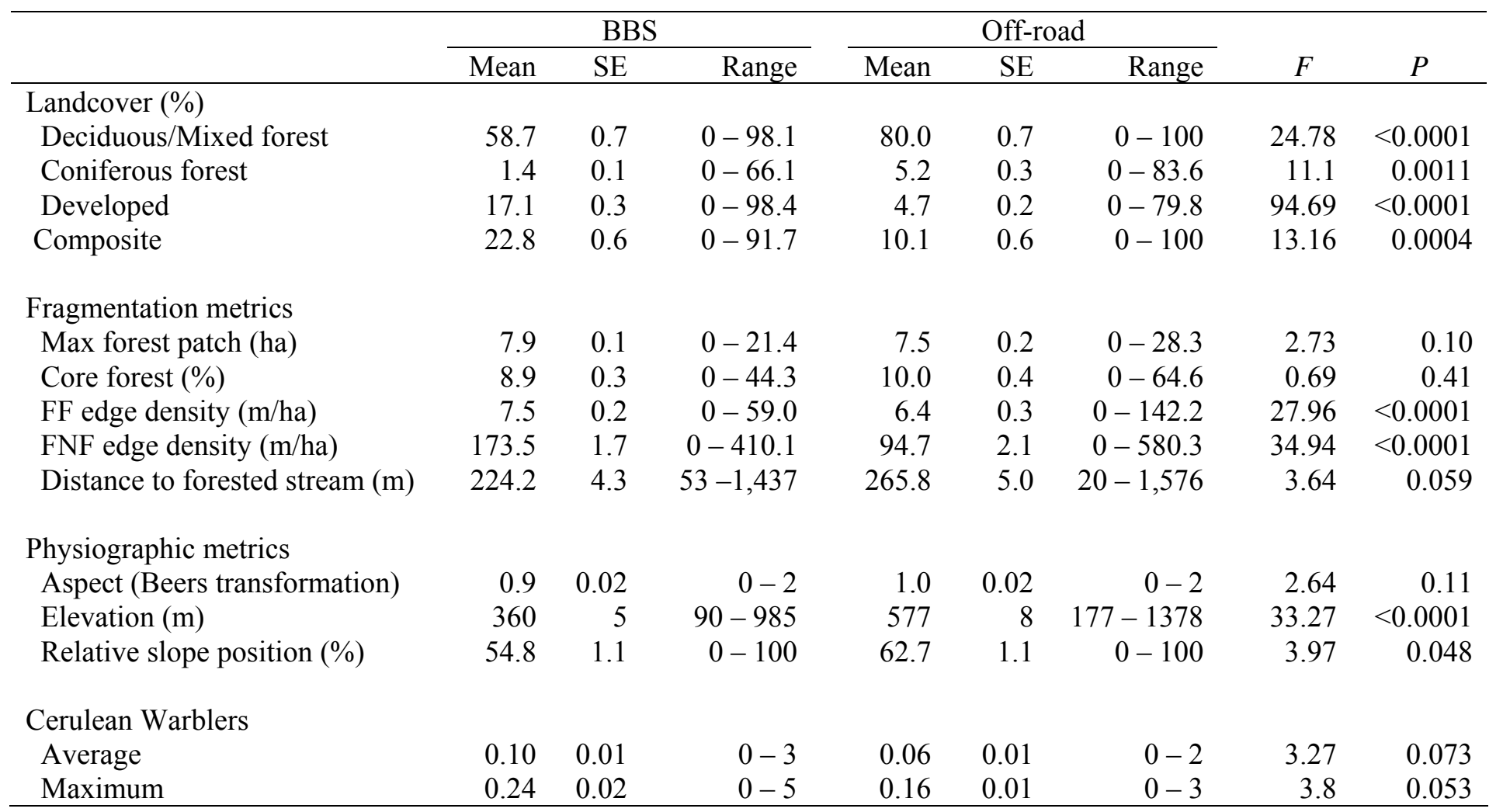


TABLE 2. Comparison of land cover and habitat metrics using 2001 NLCD data, and Cerulean Warbler detections during 1999-2003 at the set of stops at which Cerulean Warblers were detected for the BBS ( $n=253$ stops on 25 routes) and off-road ( $n=169$ stops) datasets. $(\mathrm{FF}$ edge density $=$ Forest-forest edge density, FNF edge density $=$ Forestnonforest edge density).

\begin{tabular}{|c|c|c|c|c|c|c|c|c|}
\hline & \multicolumn{3}{|c|}{ BBS } & \multicolumn{3}{|c|}{ Off-road } & \multirow[b]{2}{*}{$F$} & \multirow[b]{2}{*}{$P$} \\
\hline & Mean & SE & Range & Mean & SE & Range & & \\
\hline \multicolumn{9}{|l|}{ Landcover (\%) } \\
\hline Deciduous/Mixed forest & 74.3 & 0.9 & $17.9-94.0$ & 85.4 & 1.5 & $13.3-100$ & 6.01 & 0.017 \\
\hline Coniferous forest & 0.6 & 0.1 & $0-18.5$ & 2.3 & 0.7 & $0-76.4$ & 5.79 & 0.019 \\
\hline Developed & 15.7 & 0.5 & $6.01-49.0$ & 4.9 & 0.4 & $0-21.4$ & 56.9 & $<0.0001$ \\
\hline Other & 9.4 & 0.7 & $0-61.3$ & 7.4 & 1.3 & $0-77.4$ & 1.85 & 0.18 \\
\hline \multicolumn{9}{|l|}{ Fragmentation metrics } \\
\hline Max forest patch (ha) & 9.7 & 0.2 & $2.1-18.0$ & 10.0 & 0.6 & $0.6-28.3$ & 4.67 & 0.035 \\
\hline Core forest $(\%)$ & 13.2 & 0.7 & $0-43.7$ & 16.1 & 1.4 & $0-63.9$ & 0.28 & 0.60 \\
\hline FF edge density (m/ha) & 9.9 & 0.5 & $0-37.0$ & 7.7 & 0.8 & $0-46.3$ & 19.96 & $<0.0001$ \\
\hline FNF edge density (m/ha) & 179.4 & 3.8 & $88.8-410.1$ & 97.4 & 6.1 & $0-341.7$ & 18.58 & $<0.0001$ \\
\hline Distance to forested stream (m) & 190.6 & 7.2 & $6-707$ & 272.9 & 15.8 & $42-1,148$ & 1.28 & 0.26 \\
\hline \multicolumn{9}{|l|}{ Physiographic metrics } \\
\hline Aspect (Beers transformation) & 0.8 & 0.04 & $0-2$ & 1.0 & 0.1 & $0-2$ & 0.03 & 0.86 \\
\hline Elevation (m) & 355 & 8 & $170-848$ & 414 & 16 & $177-1294$ & 2.52 & 0.12 \\
\hline Relative slope position (\%) & 53.7 & 2.7 & $0-100$ & 66.0 & 3.0 & $0-100$ & 0.01 & 0.94 \\
\hline \multicolumn{9}{|l|}{ Cerulean Warblers } \\
\hline Average & 0.62 & 0.03 & $0.2-3.0$ & 0.47 & 0.024 & $0.2-2.0$ & 0.55 & 0.46 \\
\hline Maximum & 1.48 & 0.05 & $1.0-5.0$ & 1.28 & 0.04 & $1.0-3.0$ & 0.21 & 0.65 \\
\hline
\end{tabular}




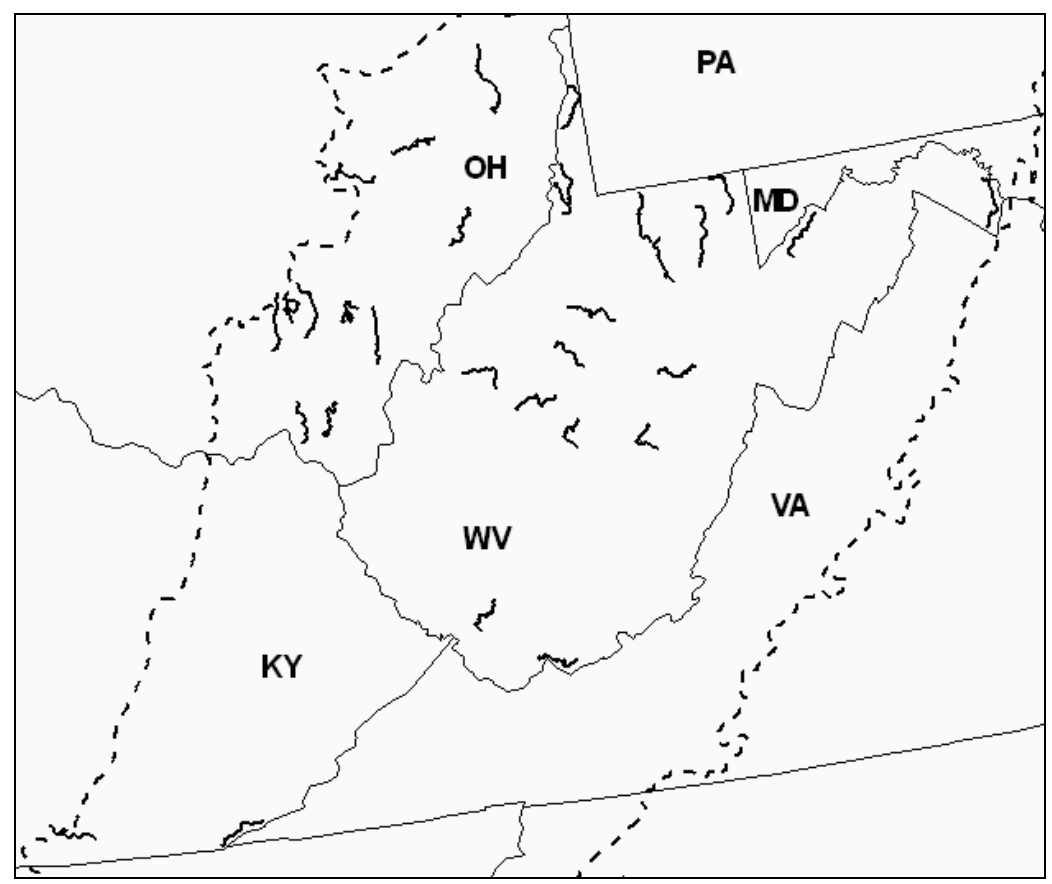

A) BBS stops ( $n=1,525$ stops on 31 routes)

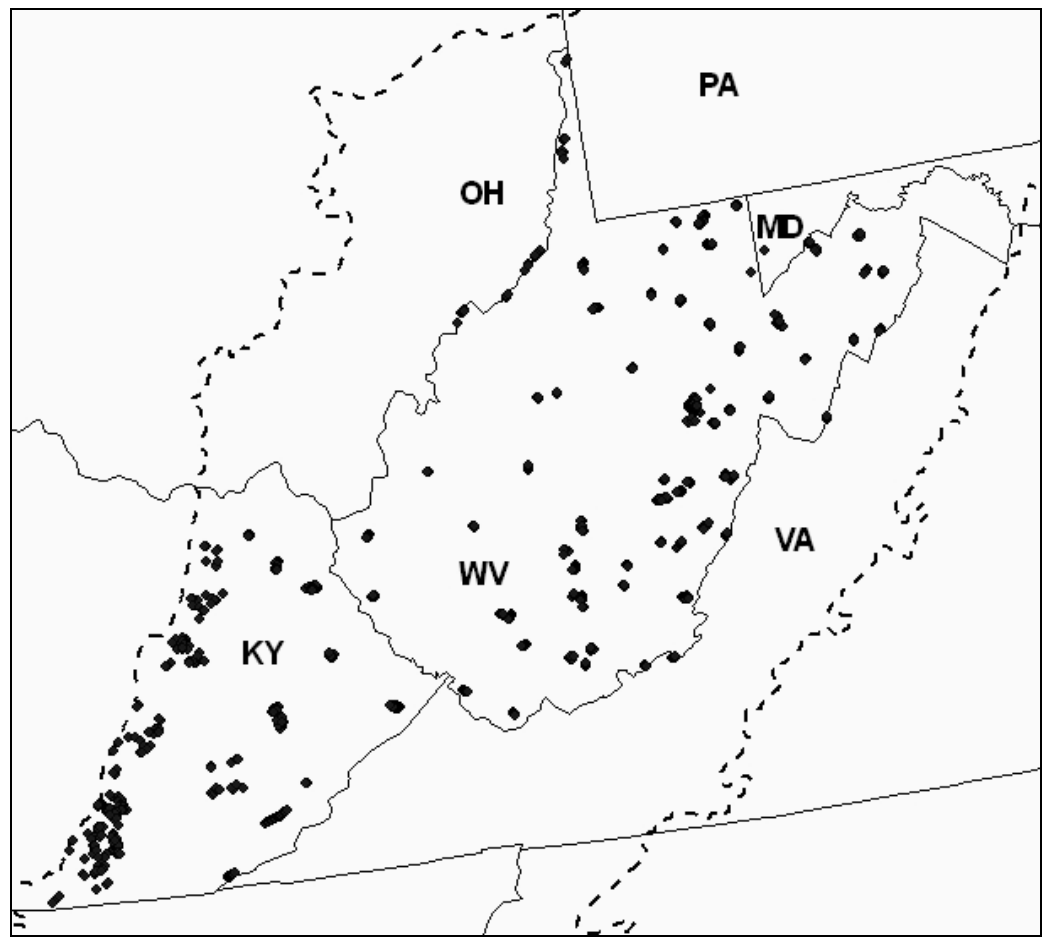

B) Off-road stops $(n=1,375$ stops $)$

FIG. 1. Study area of West Virginia, Kentucky, and Ohio portions of BCR-28 (dashed outline) with location of BBS routes and off-road stop locations analyzed in this study. 
APPENDIX 1. Land cover comparison for 2001 NLCD between section of BBS route 90044 and off-road stops; both located within West Virginia. These stops are characteristic of the patchy land cover of the Appalachian region.

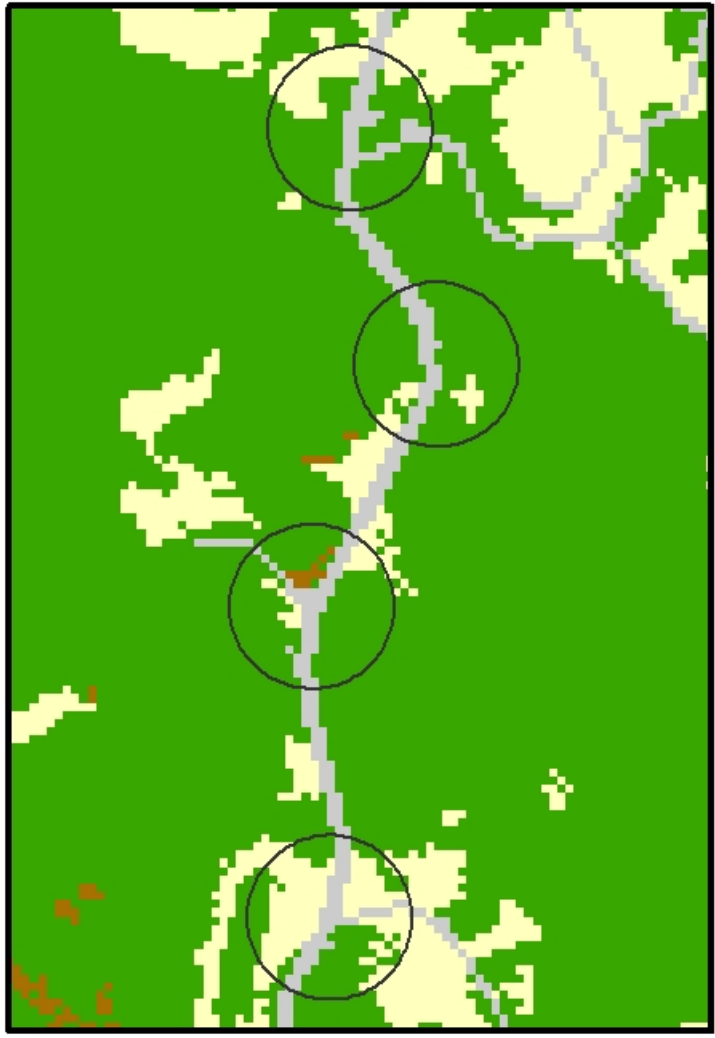

2001 BBS stop

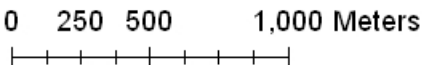

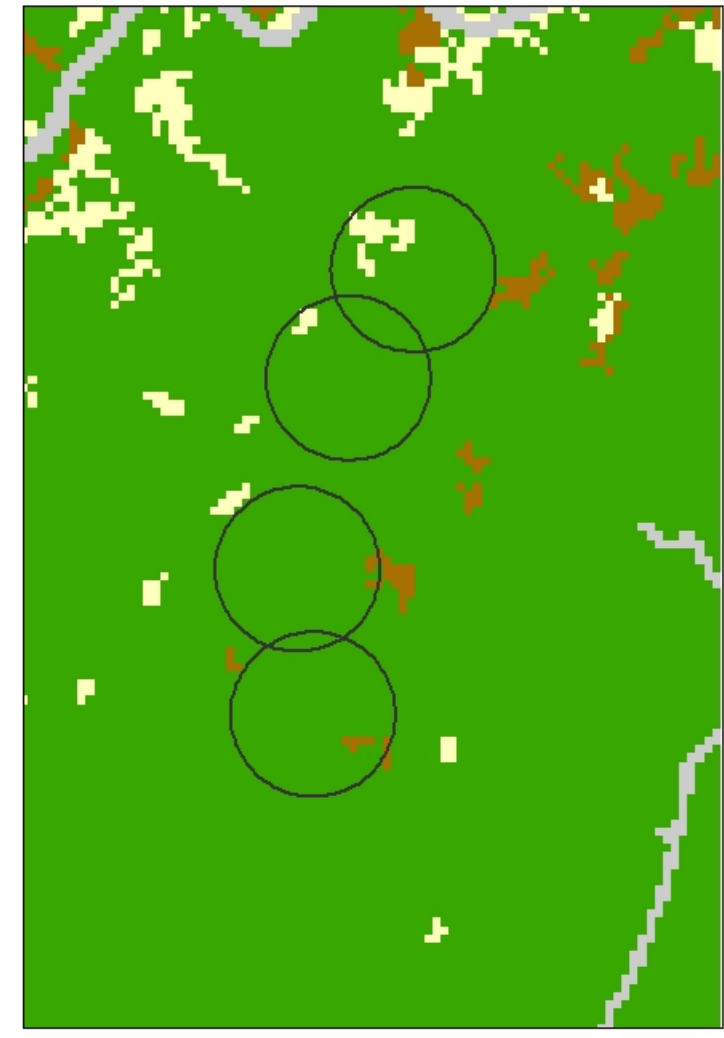

2001 Off-road stop

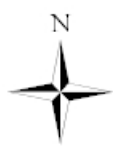

